\title{
Assessing the Impact of Changes in Household Socioeconomic Status on the Health of Children and Adolescents: A Systematic Review
}

\author{
Alexander Ryan Levesque ${ }^{1}\left[\right.$ Sarah MacDonald ${ }^{1} \cdot$ Selinda Adelle Berg ${ }^{1,2} \cdot$ Roger Reka $^{2}$
}

Received: 21 October 2020 / Accepted: 15 January 2021 / Published online: 2 February 2021

(c) The Author(s), under exclusive licence to Springer Nature Switzerland AG part of Springer Nature 2021

\begin{abstract}
Understanding how child and adolescent health is influenced by fluctuations in socioeconomic status has important public health and policy implications, as children are often subjected to both micro and macro-level socioeconomic events. This study provides the first systematic review to date on the relationship between changes in household or parental socioeconomic status and subsequent child and adolescent health outcomes. Eighty articles were identified for inclusion in this review, examining 85 different socioeconomic exposures in five categories: Income $(n=64)$, Employment $(n=14)$, Socioeconomic Mobility $(n=3)$, Education $(n=2)$, and Food Insecurity $(n=2)$. The health outcomes analyzed by these eighty articles were separated into eight discrete categories, with many articles examining outcomes in more than one category: Anthropometric Measurements $(n=21)$, Cognition and Development $(n=15)$, Dental Health $(n=3)$, Health Behaviours $(n=9)$, Mental Health $(n=12)$, Overall Parent/Guardian Assessed health $(n=6)$; Physical Health Outcomes $(n=11)$, and Socio-Emotional Behaviour $(n=30)$. Several consistent patterns emerged in the literature, such as a link between increased income and improved, or decreased income and deteriorating, cognition, dental health, and physical health. The results of this review suggest a need to replicate current studies in diverse geographies to expand generalizability and clarify regional patterns. There should also be an effort to go beyond income, and employment, to assess the relationship between less frequently studied socioeconomic exposures and child health outcomes.
\end{abstract}

Keywords Child health $\cdot$ Adolescent health $\cdot$ Mental health $\cdot$ Physical health $\cdot$ Socioeconomic transitions $\cdot$ Parental employment

\section{Introduction}

Research in the past few decades has shown that children exposed to low-household SES face an increased risk of health problems and chronic conditions and worsened severity of health issues that develop (Condliffe and Link 2008). The negative effects of low-SES on children's health can be identified before a child has reached school age, and these effects persist, and frequently worsen, as children grow older (Currie and Stabile 2003). The accumulative and long-term effects of SES on child and adolescent health are therefore well established. What is less clear, however,

Alexander Ryan Levesque

alevesq8@uwo.ca

1 Schulich School of Medicine \& Dentistry, University of Western Ontario, London, ON, Canada

2 Leddy Library, University of Windsor, Windsor, ON, Canada is the relationship between changes in household SES and subsequent child and adolescent health. Much of the current literature on the influence of SES on child and adolescent health comes from research comparing children from lowSES backgrounds, whether cross-sectionally or longitudinally, with children from higher-SES backgrounds. This research has limitations, as children do not always remain in one income group throughout their lifetime. Furthermore, children from any SES background can be subjected to SES shocks that, while perhaps not changing the children's overall SES level, could have consequences for their health. For example, the 2008 economic crisis was associated globally with substantial harms to children's health, including increased infant mortality, worsening nutrition habits, increased violence against children, and growing inequalities in children and adolescent's health-related quality of life (Rajmil et al. 2014). These findings illustrate the importance of understanding the ramifications of changes in SES, both long and short-term, on children's health. To further this 
understanding, this study offers the first review to synthesize and analyze the current literature on the impact of changes in SES on the health of children and adolescents over time.

Knowledge of the mechanisms linking SES changes and child health is beneficial, from a public health perspective, for assessing and responding to the potential health effects of wide scale socioeconomic crises such as the 2008 Great Recession, which had a dramatic impact on the economic wellbeing of families (Reinhard et al. 2018), or even the COVID-19 pandemic, which is projected to drastically increase global unemployment and poverty (Buheji et al. 2020). On a more meso scale, increased knowledge of the ramifications of socioeconomic changes on children's health could also help inform policy decisions in regard to factory closures, long known to be associated with increased morbidity among adults (Beale and Nethercott 1985), and other local economic events. It is not just the negative effects of socioeconomic changes on children's health that are important, however. Greater knowledge of the impact of positive changes in SES on child health could be helpful in the design and assessment of interventions and policies aimed at increasing parental employment or decreasing child poverty (Kagura et al. 2016). Beyond the public health implications, such information could also be useful, on a micro level, to aid health and social professionals in responding to the consequences of changes in family SES. As an example, in Norway enrollment in quality, regulated childcare centers was found to mitigate the effect of changes in SES on young children's behavioral problems (Zachrisson and Dearing 2015). As Norway provides universal access to subsidized and regulated childcare, this finding supports health and social services encouraging enrollment in regulated childcare, especially among low-income families. It is evident that increased knowledge of the effect of SES changes on child and adolescent health could have myriad implications for the design and implementation of health policy and social services.

\section{Current Study}

The current study aims to provide a better understanding of the effect of changes in household, familial, or parental socioeconomic status on the health and wellbeing of children. The goal of this research is to synthesize the current body of knowledge on the impact of changes in income, employment, education, and other measures of socioeconomic mobility on the physical, mental, and overall health of children and adolescents. To date, there has been no prior systematic review on this subject, and thus this review will serve as an important reference point for ongoing and future research. This synthesis will identify current gaps in the literature as well as interesting findings that warrant further investigation and serve as a guide to subsequent studies on this topic. The consolidation of current knowledge on this subject should also be informative for the development of public health policy, at the macro and meso levels, aimed at mitigating the detrimental effects of socioeconomic events on children.

\section{Methods}

\section{Search Strategy}

The complete protocol for this review is registered on PROSPERO, ID CRD42020160653. Articles were retrieved from bibliographic database searches conducted on October 29, 2019 , covering all indexed publications from the inception of the database to the date of the search. The databases used were MEDLINE, Embase, PsycINFO, CINAHL and Sociological Abstracts. These databases were selected as they provided coverage in the topic areas of health sciences, life sciences, and the social and behavioral sciences.

To identify relevant literature pertaining to the research question, a search strategy was developed by a librarian with expertise in systematic reviews that included terms and headings reflecting four concepts: children, longitudinal study designs, family, and changes to socioeconomic status (see Online Resource 1 for complete search strategies). Terms related to health outcomes were not included in the search strategy, due to the breadth of possible outcomes. Studies with relevant health outcomes were identified during the screening process. Different combinations of search terms were tested to balance precision and sensitivity, before using the PRESS checklist to evaluate the research question translation, use of operators, selection of subject headings, and spelling (McGowan et al. 2016). Additional articles were identified via screening of the reference sections of included articles and a search of gray literature, meaning literature not published in traditional academic databases, using Google and Google Scholar.

\section{Inclusion Criteria}

To be included in this review studies had to meet the following criteria: (1) sample population included children and adolescents 18 years of age or younger; (2) study examined the effect of a change in parental, familial, or household SES; (3) study included at least one health outcome, defined broadly to include general health, anthropometric measurements, chronic mental and physical health conditions, cognition, psychological development, health behaviors, and any other physical or mental health outcomes; (4) data was longitudinal, not solely retrospective or cross-sectional, in 
nature, with at least two measurements of SES at different points in time; (5) analysis was quantitative or mixed-methods, not solely qualitative; (6) study was published in English or French. The inclusion criteria included no restrictions for year of publication or geographical region.

If a study's sample included participants over the age of 18 , the study was included and only the results for those participants 18 years of age or younger were extracted. In eight articles adolescents younger than 18 were not analyzed separately from those over age 18 . In these cases, the studies were still included for their potential relevance to the research questions addressed by this review. The upper age range of the samples in these studies ranged from 19 to 22 . Determining an exact chronological definition of adolescence is difficult as the meaning of adolescence has changed over time and varies substantially between different cultures and legal jurisdictions (Curtis 2015). Current official definitions for adolescence in the U.S., for example, have an upper limit ranging from 19 to 25 years of age (Curtis 2015). In all eight studies in question the samples were referred to as adolescents, although two studies also used the term young adults interchangeably. Although the focus of this review is on children and adolescents up to age 18 , these studies were included as recognition of the impreciseness inherent in defining adolescence. A special note is made, however, when each study is first referenced in the "Results" section and the impact of their inclusion is assessed in the "Discussion" section. Articles that examined only subjective reports of socioeconomic status or financial wellbeing, such as the Mac Arthur Scale of Subjective Social Status (see Goodman et al. 2001), were excluded, as this review is focused on the effect of changes in objective measures of household socioeconomic status, such as household income or parental employment status, on child and adolescent health outcomes. Although this review employs a broad definition of health, including cognitive and psychological outcomes, studies that exclusively examined child/adolescent educational outcomes (e.g. academic grades), deviant and criminal behaviors, or social supports were excluded.

\section{Screening Process}

All studies identified by the database search $(n=3871)$ were first de-duplicated by a single author (RR) in EndNote using the validated Bramer Process (Bramer et al. 2016), removing 1317 duplicates. The remaining entries were then uploaded into Covidence, where a further 284 duplicates were removed leaving 2270 unique entries. The title and abstract of these entries were screened for relevance by two authors (ARL, SM) with a third (SAB) settling disagreements. The same authors then screened the full text of all articles identified as potentially relevant during the title and abstract screen. A detailed description of the entries excluded at each step in the screening process, as well as the reasons for exclusion in the full-text screening, are displayed in Fig. 1. All studies identified during the hand search of reference lists and gray literature search were also screened by the same two authors (ARL, SM) with the third author again settling disagreements (SAB). Before each screening step the authors practiced applying the screening criteria to a sample set of ten articles, and then met to discuss the screening results as a team to ensure there was common understanding of how to interpret and use the screening criteria at each stage in the review.

\section{Data Extraction Process}

Data was extracted from the final set of included studies $(n=80)$ by two authors (ARL, SM) with disputes again settled by the third author (SAB). The information extracted from each study included year of publication, geographic location of the study, study period, sample size, sampling method(s), respondent demographics, details on the analytic method(s), exposure of interest, outcome of interest, control variables, and the results of the study. When a study included exposures or outcomes that were not relevant to this systematic review only the relevant information was extracted.

To properly capture the findings of each study, the unadjusted and adjusted results were extracted as well as the authors' written summaries of the results. A quantitative synthesis and comparison of these findings would be inappropriate due to the heterogeneity of the analytical methods included in this review, so instead the results are compared thematically based on the outcome examined.

\section{Assessment of Article Quality and Risk of Bias}

Article quality and risk of bias was assessed using The Newcastle-Ottawa Scale (NOS) for cohort studies (Wells et al. 2014), modified to fit the parameters of this review (see Online Resource 2). The NOS assigns each study a numerical score ranging from 0 to 9 based on sample selection, comparability, and the measurement of the outcome variables. For sample selection, studies are assigned one point for each of the following: a completely or partially representative sample, a non-exposed cohort drawn from the same community as the exposed cohort, ascertainment of exposure from administrative records or a structured interview, and taking methods to ensure that the sample did not have the outcome prior to the exposure. Articles were also assessed on the comparability of the exposed and nonexposed samples, based on the confounding variables controlled for in each study. One point was assigned if studies adjusted for three or more socioeconomic or demographic variables, such as respondent/parental age, respondent gender, household income, or parental education. A point was 


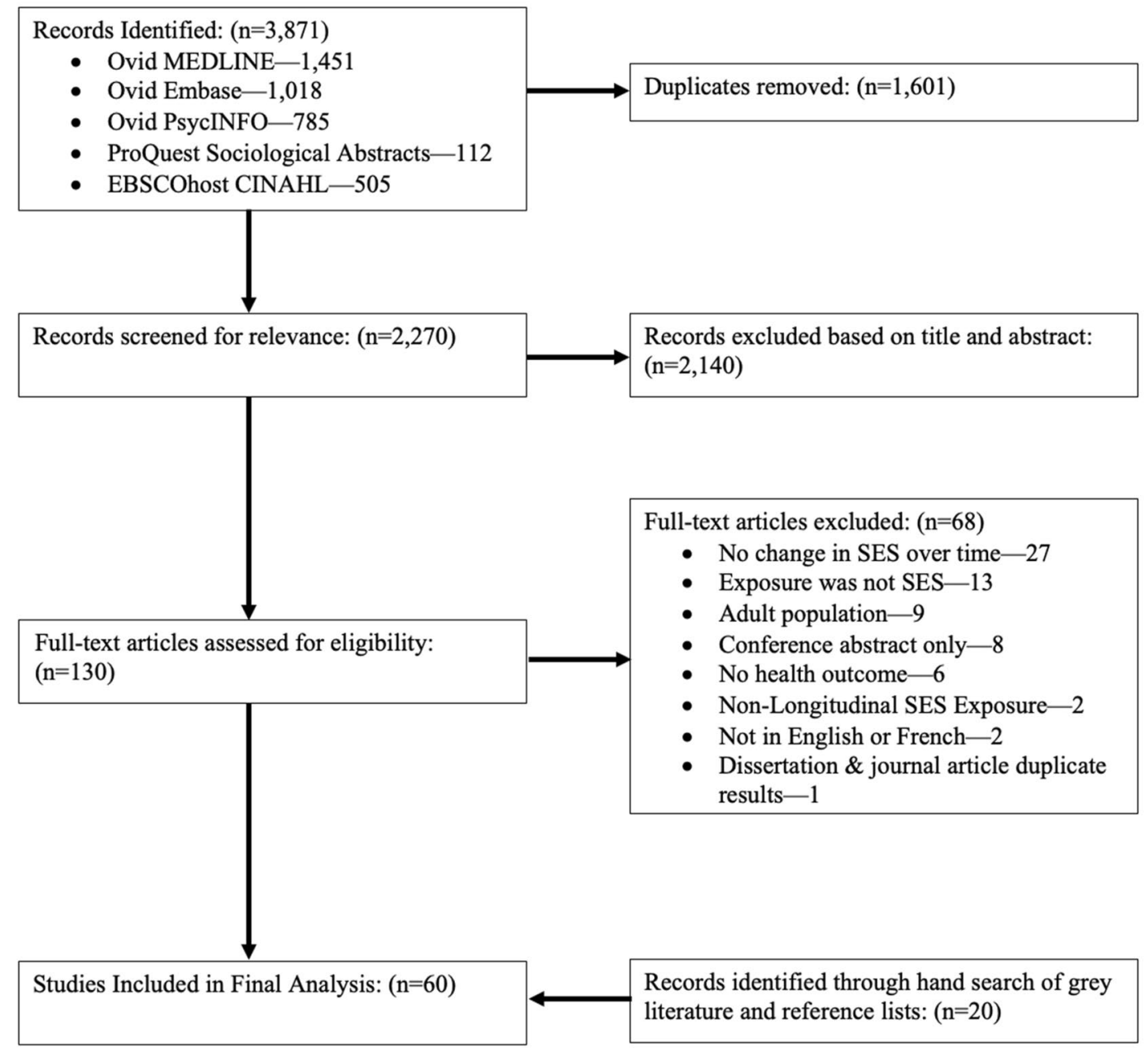

Fig. 1 PRISMA analysis

also given to studies that controlled for any child or familial health history variables that could confound the relationship between the socioeconomic exposure and the measured health outcome. Studies that controlled for child-level fixed effects were deemed to have met both criteria. In other words, comparability points were assigned to studies that attempted to promote comparability between the exposed and non-exposed samples, either through adjusting for common socioeconomic/demographic confounders or accounting for the influence of past health history. Finally, points were assigned to studies that used a reliable method to assess the health outcome, allowed for greater than a year of follow-up, and had adequate levels of follow-up or used proper methods to account for attrition.

\section{Results}

\section{Article Demographics}

Figures 2, 3 and 4 summarize demographic information about the included articles, including year of publication, location of the study, and the age composition of participants at the time of the exposure and outcome. This information is also displayed individually for each article in Table 1.

Figure 2 illustrates that the majority of articles included in this review were published after $2009(\mathrm{~N}=60,75.0 \%)$, and no articles published before 1991 were identified for inclusion. Figure 3 displays the geographical distribution of included papers grouped into clusters by continent. More than half of the articles $(\mathrm{N}=44,55.0 \%)$ examined populations in North America, all within Canada and the U.S. A further 20 articles $(25.0 \%)$ examined European populations: $13(16.3 \%)$ in the U.K. and Ireland, and the remaining seven $(8.7 \%)$ in Nordic countries. 
Fig. 2 Article distribution by year of publication

Fig. 3 Article distribution by country of study

Fig. 4 Article distribution by age of exposure $(\mathrm{N}=89)$ and outcome $(\mathrm{N}=81)$
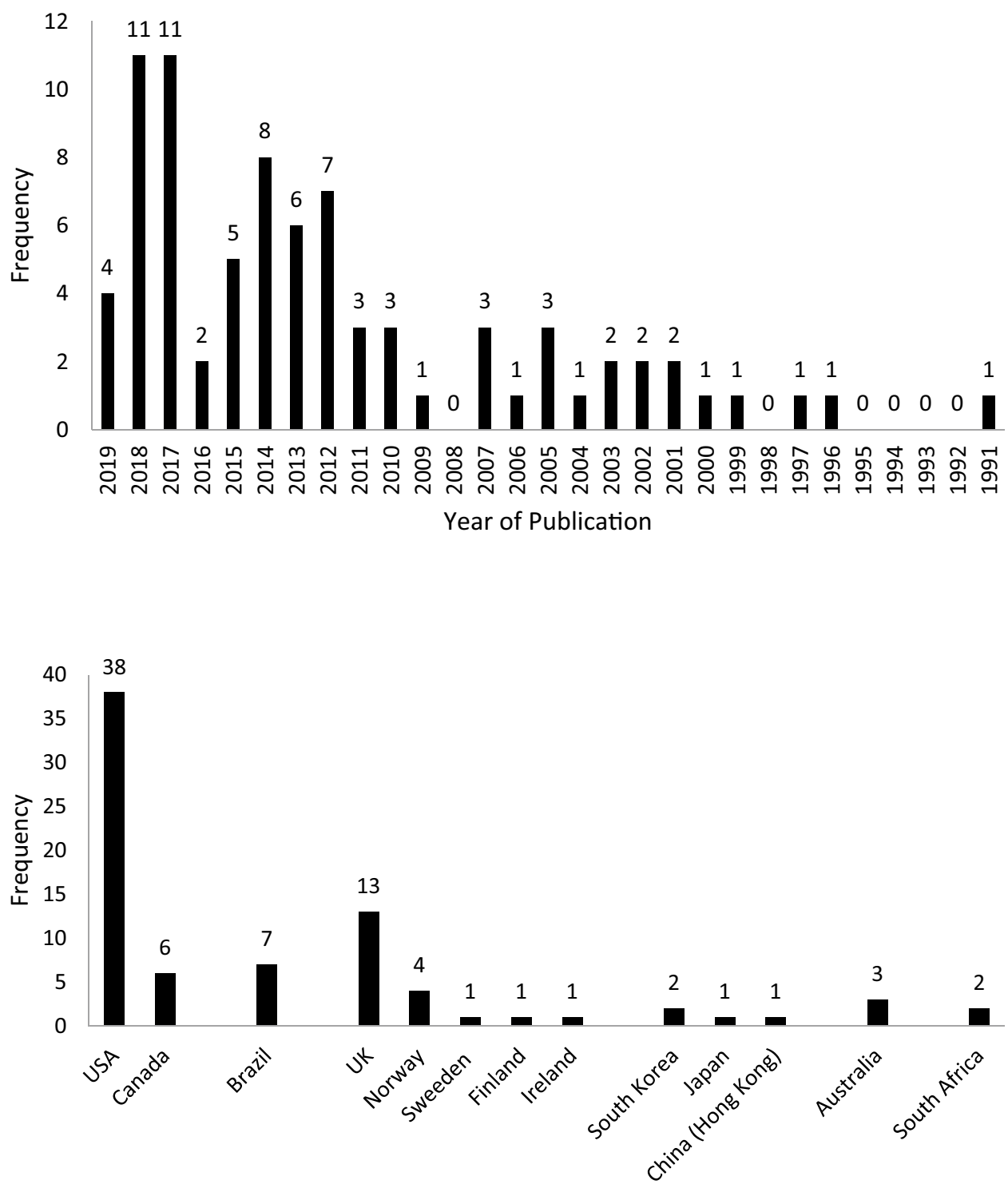

Country of Study

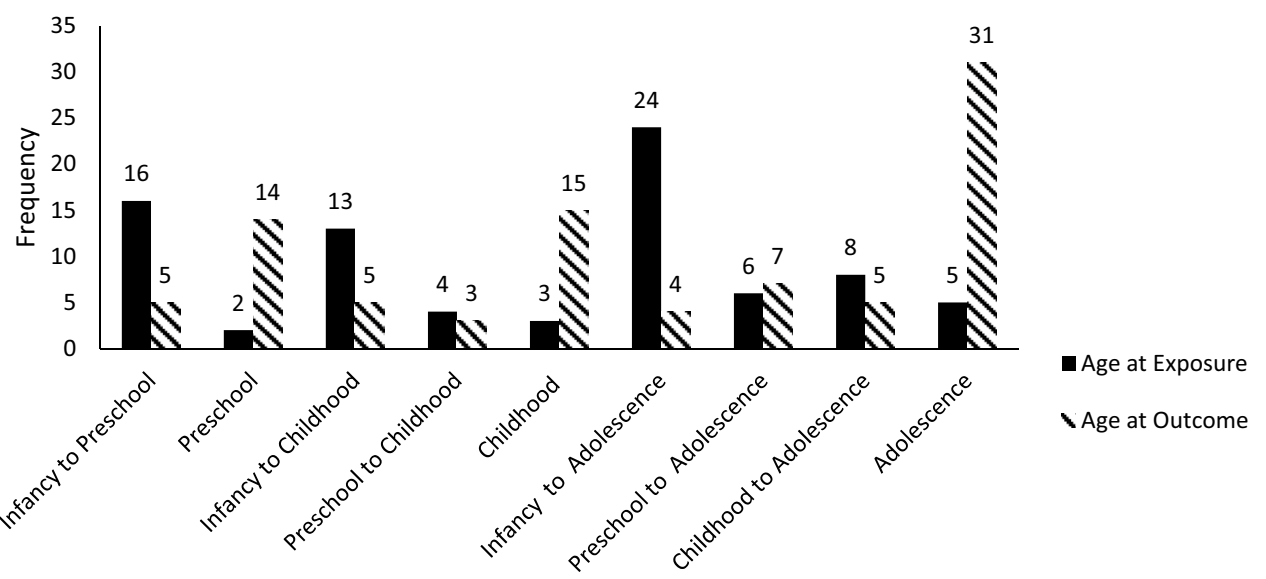

Age at Exposure or Outcome 


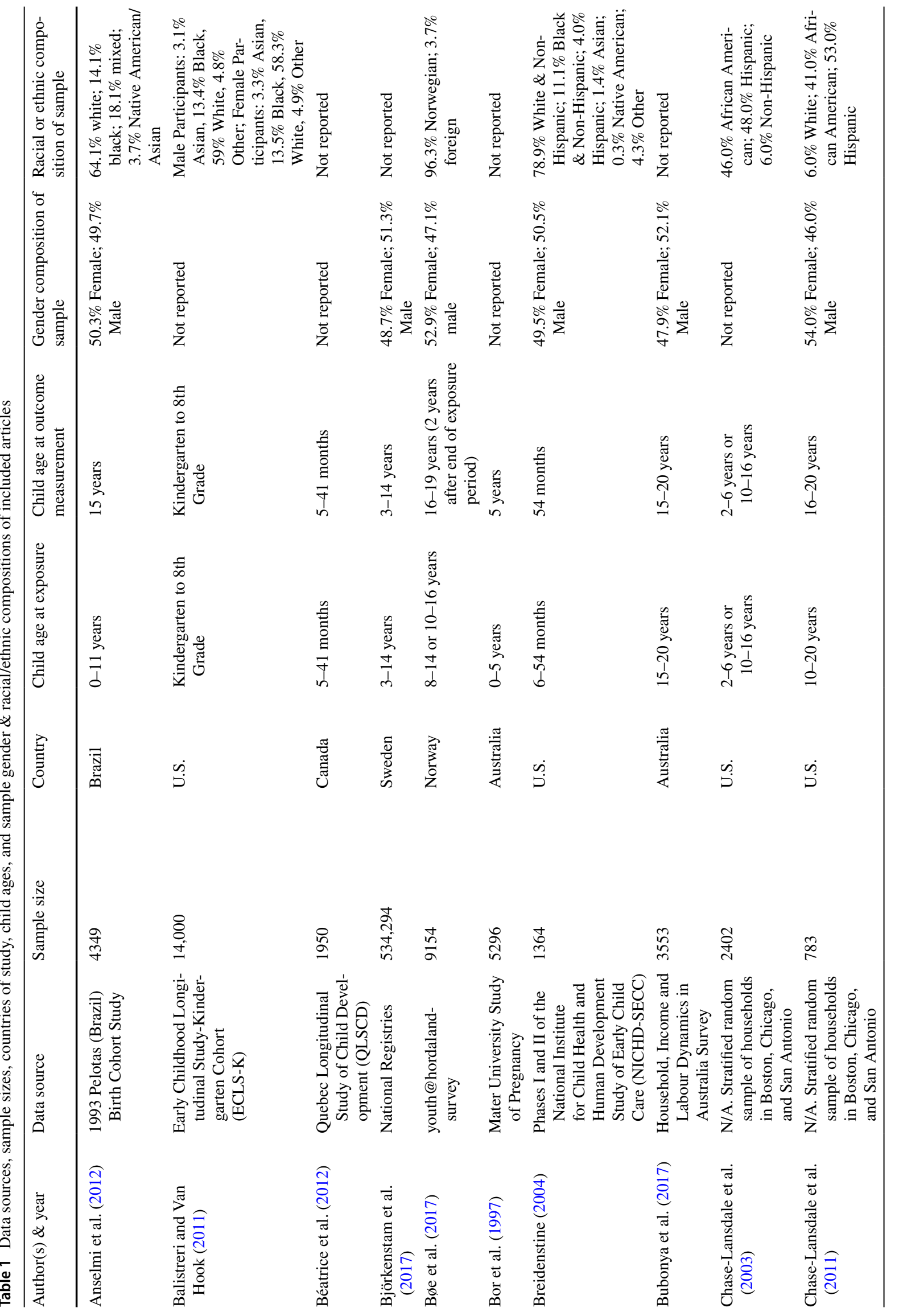




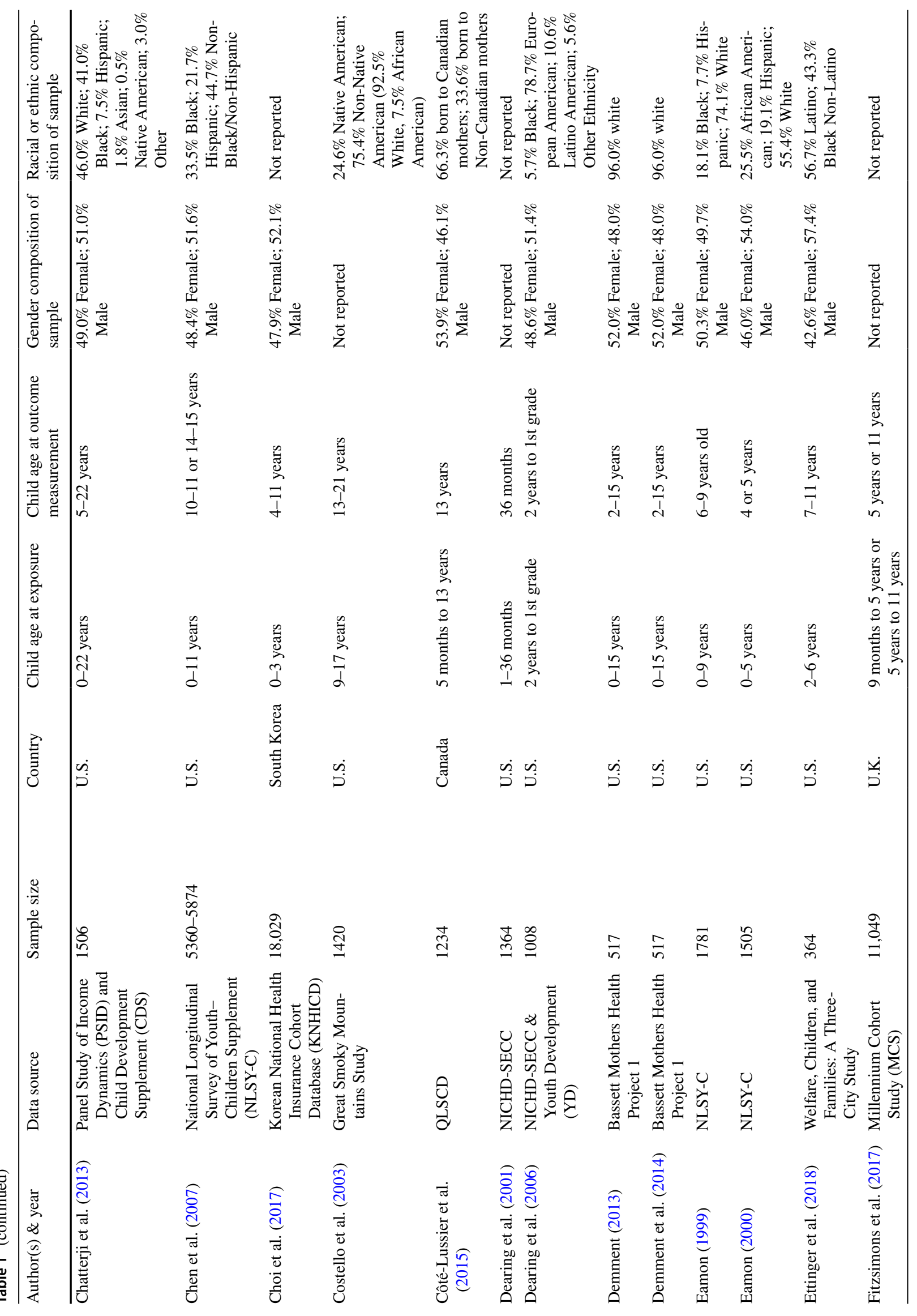




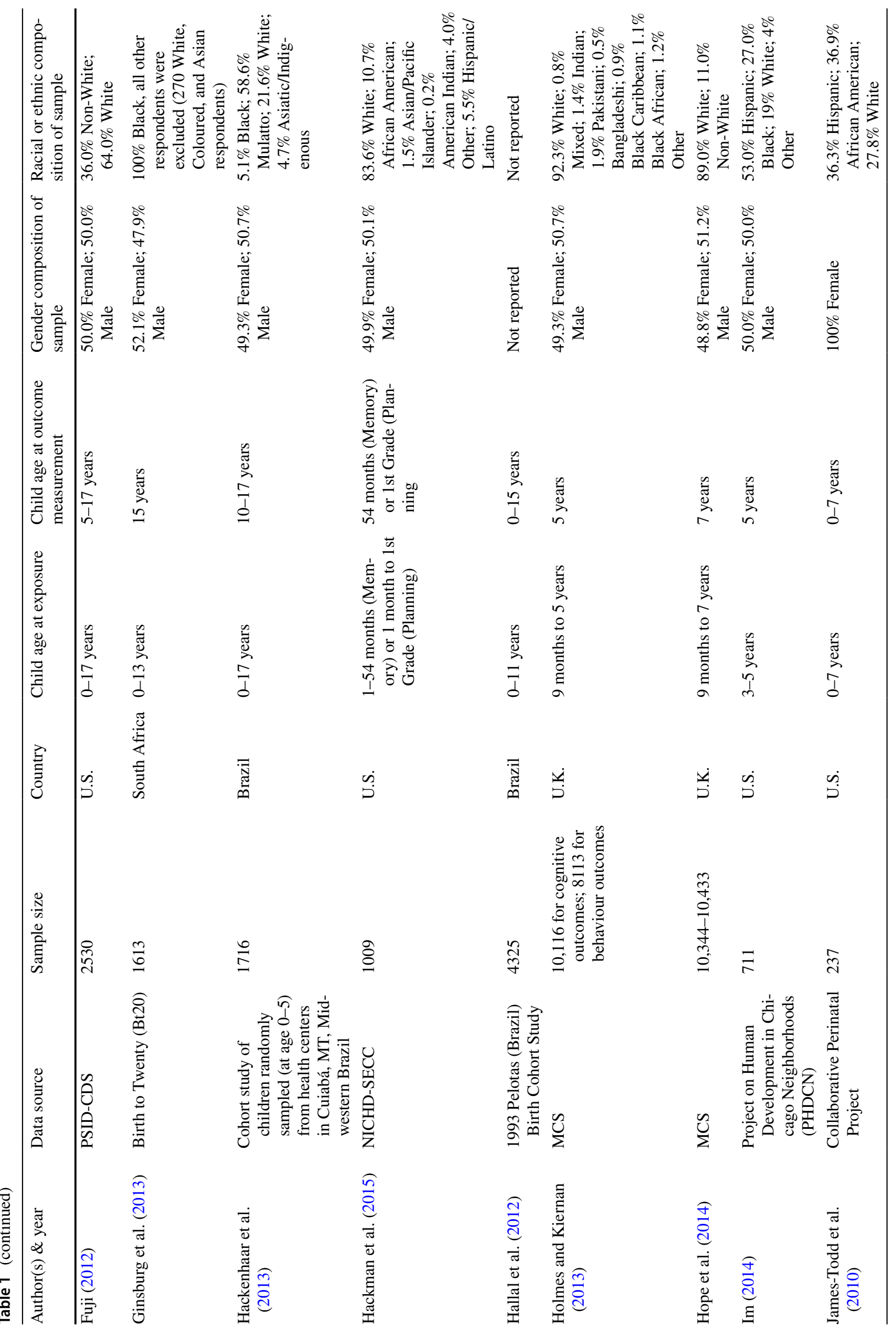




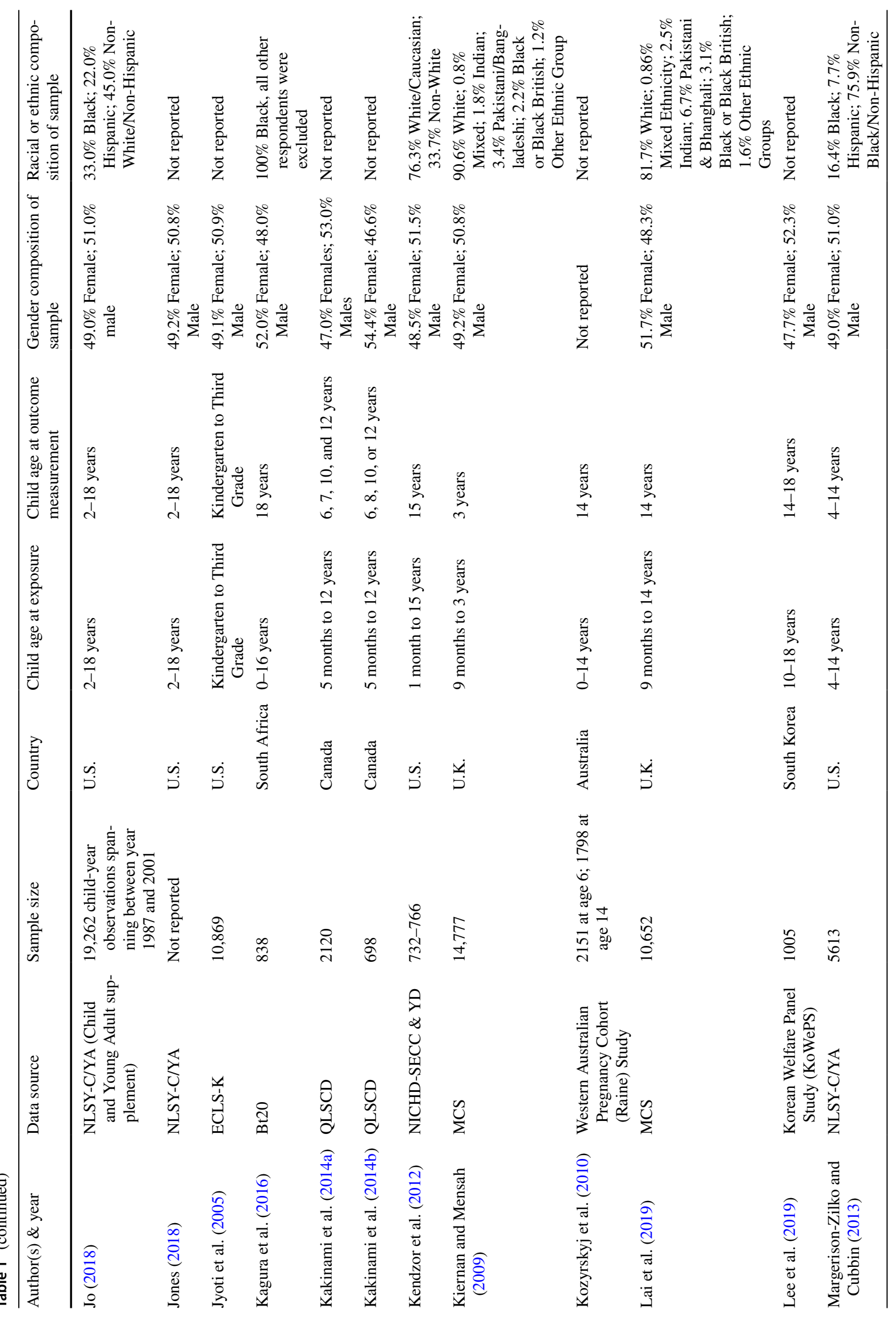




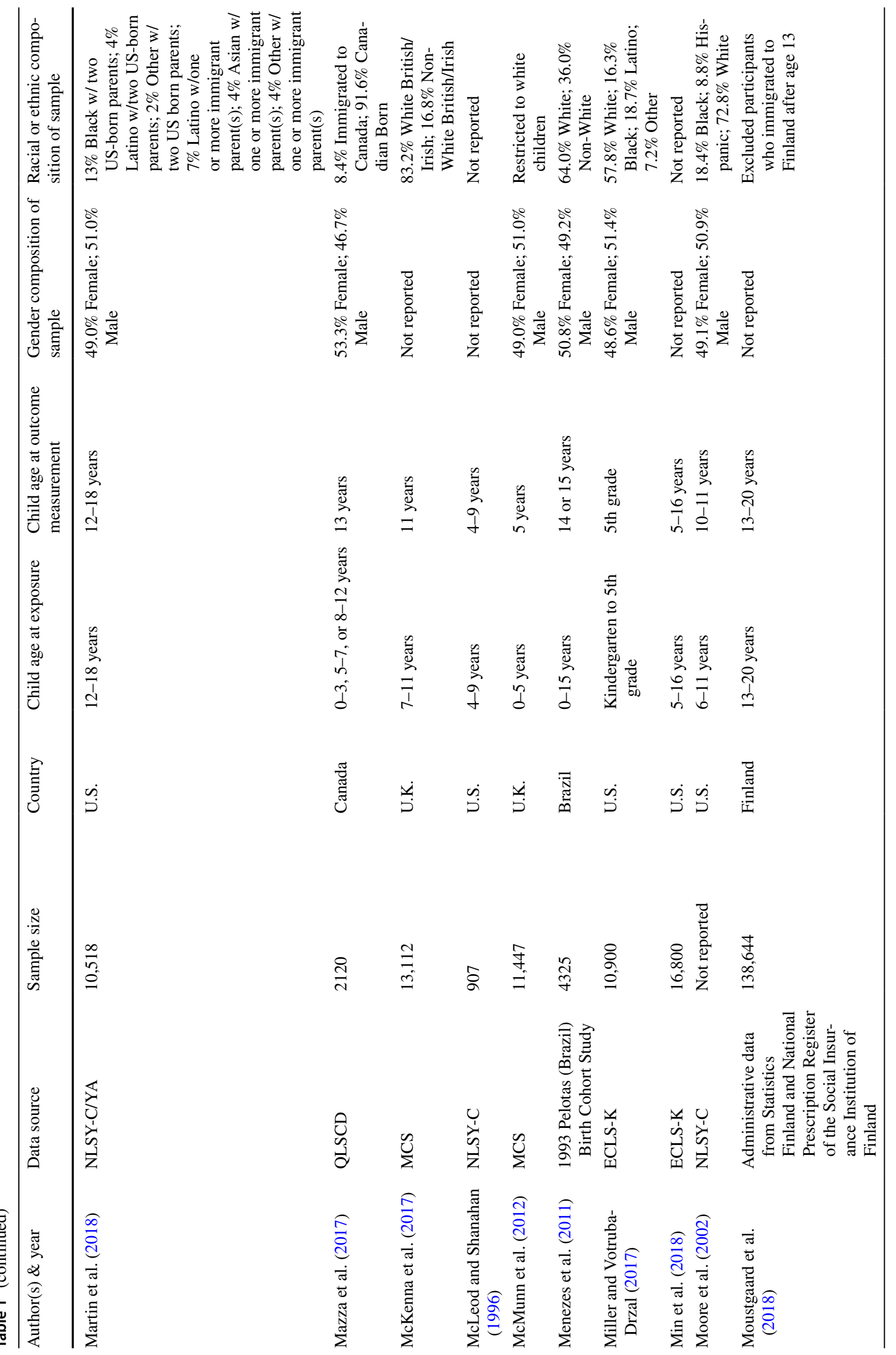




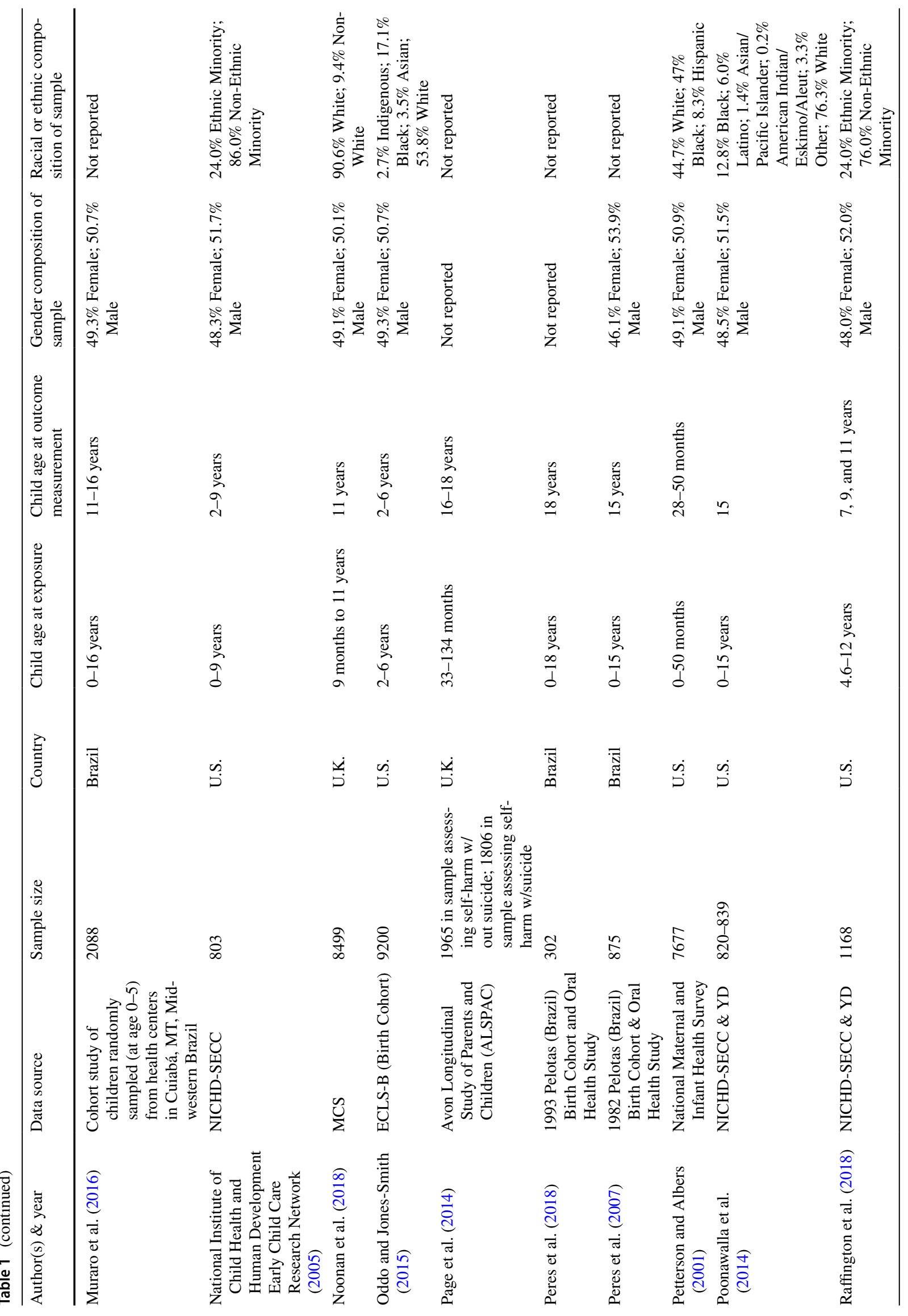




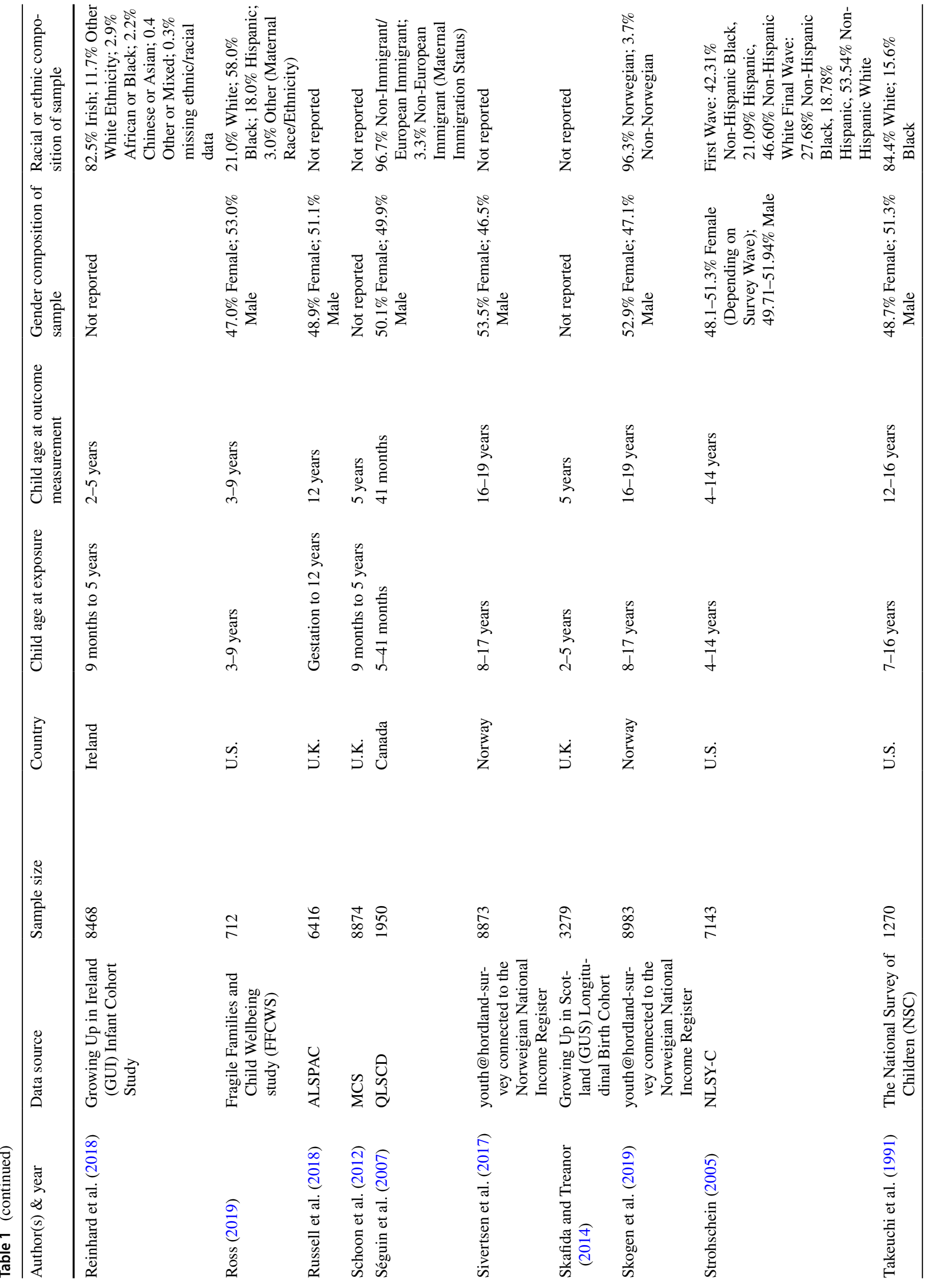




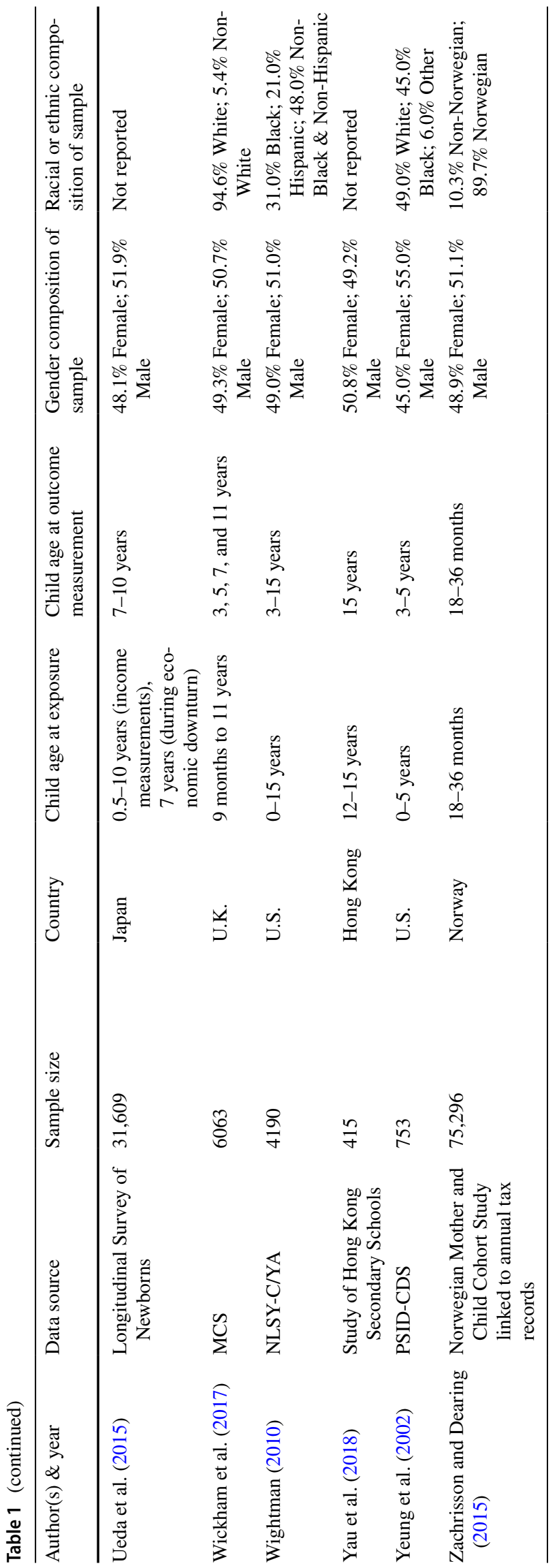

Figure 4 summarizes data on the age at exposure and outcome for the included studies. To facilitate interpretation, studies were grouped into categories based on the age of their sample at the start and end of measurement. For the purpose of this review, Infancy was defined as ages 0-2, Preschool as ages 3-5, Childhood as ages 6-11, and Adolescence as ages 12-18. If studies examined two different exposures, outcomes, or samples at different age groups, both age groups included. According to Fig. 4, the majority of the exposures were assessed from infancy to a later age $(\mathrm{N}=53,65.4 \%)$, with $24(29.6 \%)$ starting the measurement of the exposure in infancy (between age 0 and 2) and ending measurement in adolescence (between age 12 and 18). The outcome variables, on the other hand, were mostly measured within a single age group, with 31 outcome measurements (34.8\%) occurring in adolescence, 16 occurring in childhood $(18.0 \%)$, and 14 (15.7\%) occurring in preschool. All of the exposures were assessed longitudinally, as a criterion for inclusion. As such, most exposures were measured across age groups whereas most of the outcomes were assessed in a single age group.

Information on the gender and racial/ethnic composition of included studies are also displayed in Table 1. Overall, $62(77.5 \%)$ of the included articles reported information on the gender composition of their samples. Only one of these 62 articles included only female participants, and no articles included only male participants. In the remaining 61 papers, the proportion of the sample that was female ranged between 42.6 and $54.4 \%$. In comparison, only 54 (67.5\%) of included studies reported information on the racial/ethnic composition of their samples. Of these 54 papers, both of those examining South African populations restricted their samples to black participants and one paper examining a UK population restricted its sample to white participants.

\section{Article Methods: Sample Size, Surveys, and Bias}

Figure 5 and Table 1 display the distributions of sample sizes for the included studies. Two papers did not report a sample size. Overall, there was a wide distribution of sample sizes, with the smallest study reporting a sample size of only 237 respondents (James-Todd et al. 2010), and the largest having a sample of 534,294 respondents (Björkenstam et al. 2017). Nearly $21 \%$ of the studies reported a sample size smaller than 1000, and four studies reported a sample size $>20,000$. Table 1 also displays information on the data source(s) used by each included article. Of particular note are the three countries where all of the studies utilized data covering only specific regions: five of the seven articles studying Brazilian populations used the Pelotas, Brazil Birth Cohort and the other two used data from a cohort in Cuiabá, Brazil; all four Canadian studies relied on data from the Quebec Longitudinal Study of Child Development (QLSCD); and both 
Fig. 5 Article distribution by sample size

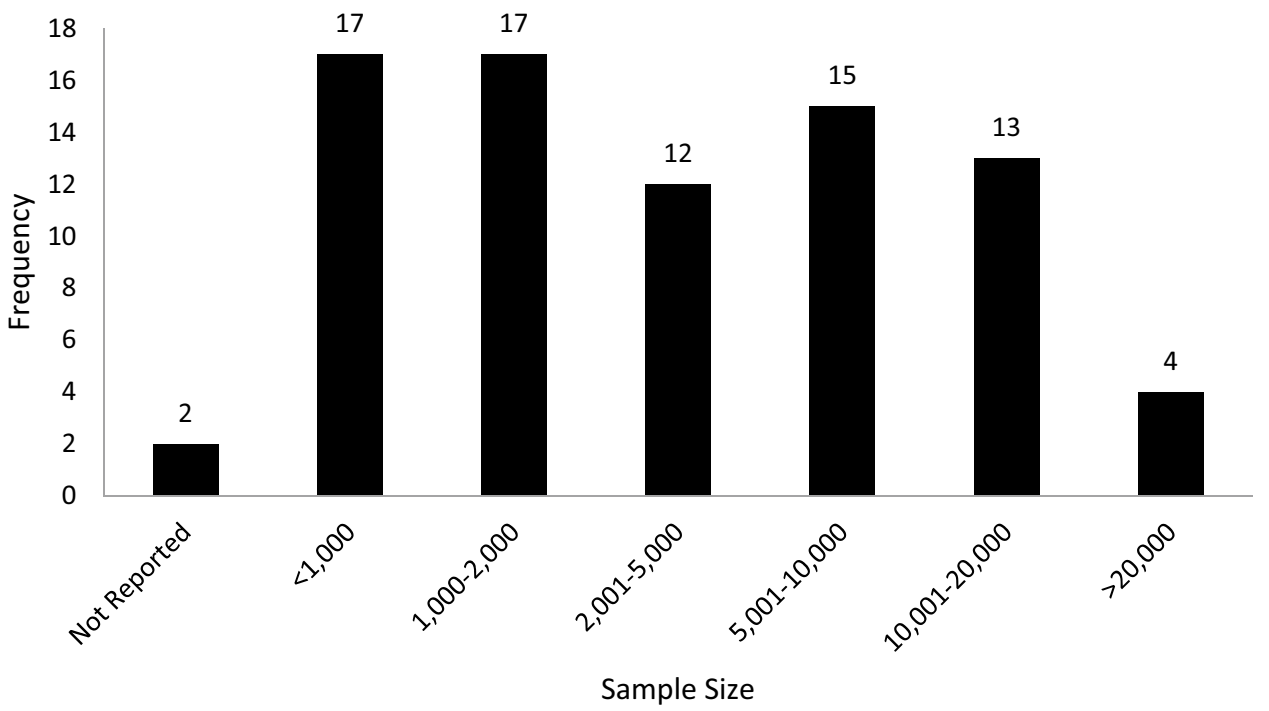

South African studies relied on the Birth to Twenty Dataset, which drew only from Soweto, a township of Johannesburg. In other words, the data sources used in all three countries sample only from specific regions, rather than at the national level, so the results may not be generalizable to the countries as a whole.

Figure 6 displays the distribution of overall NOS scores for the included studies, and Table 2 displays the individual scores for each included article for each NOS category: Selection, Comparability, and Exposure. The mean NOS score for all included papers was 7.5 out of 9 overall, 3.6 out of 4 for Selection, 1.6 out of 2 for Comparability, and 2.4 out of 3 for Exposure. Of the 80 studies, $83.8 \%$ had an overall score of 7 or higher, and only one article scored a 3 (Hackenhaar et al. 2013). The majority of the included studies received a perfect score in the Exposure category $(n=42,52.5 \%)$, meaning they used a reliable method to assess the health outcome, allowed greater than a year for follow-up, and properly accounted for survey attrition. Among the remaining studies, the most common concern was a loss of $>10 \%$ of the original sample to follow-up without any methods used to account for attrition $(n=29$, $36.3 \%$ ). In terms of Comparability, only seven papers $(8.8 \%)$ did not control for at least three SES confounders or for any confounders related to child or parent health history, 21 papers $(26.3 \%)$ only controlled for one or the other, and the remaining 52 papers $(65.0 \%)$ controlled for both.

The Selection category had the highest relative mean, with no studies scoring a 0 or 1 , out of 4 , and only three studies scoring a 2 . The overwhelming majority of the studies relied on a sample that was at least partially representative, drew the non-exposed cohort from the same sample as the exposed, and ascertained the exposure through a structured interview $(n=72,90.0 \%)$. The most common obstacle, therefore, was failing to ensure that the sample did not have
Fig. 6 Article distribution by total Newcastle-Ottawa score

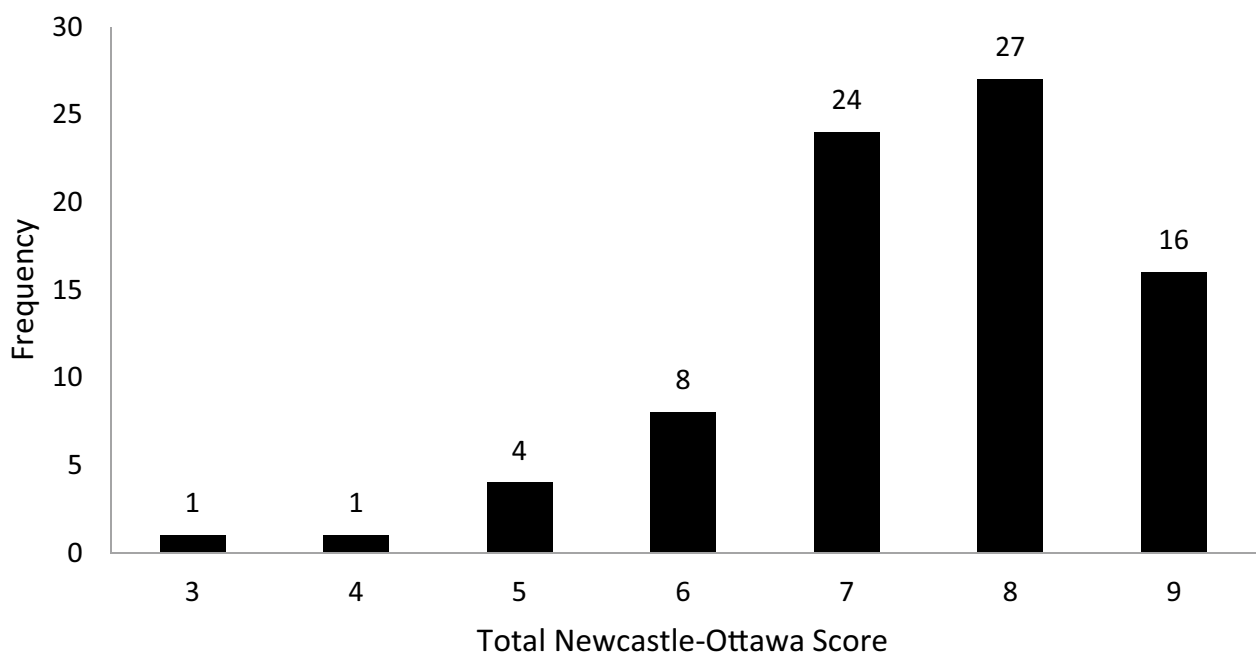




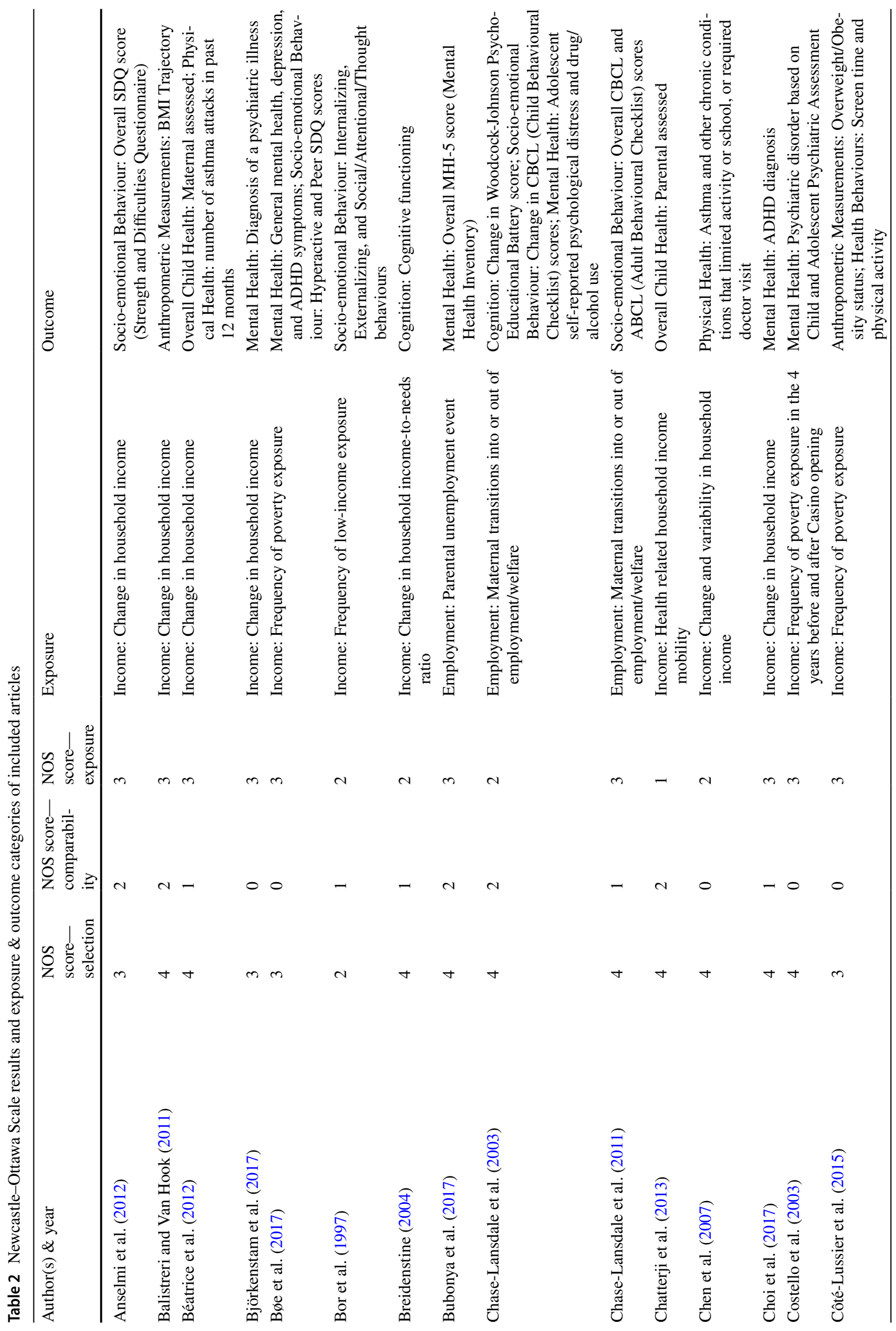




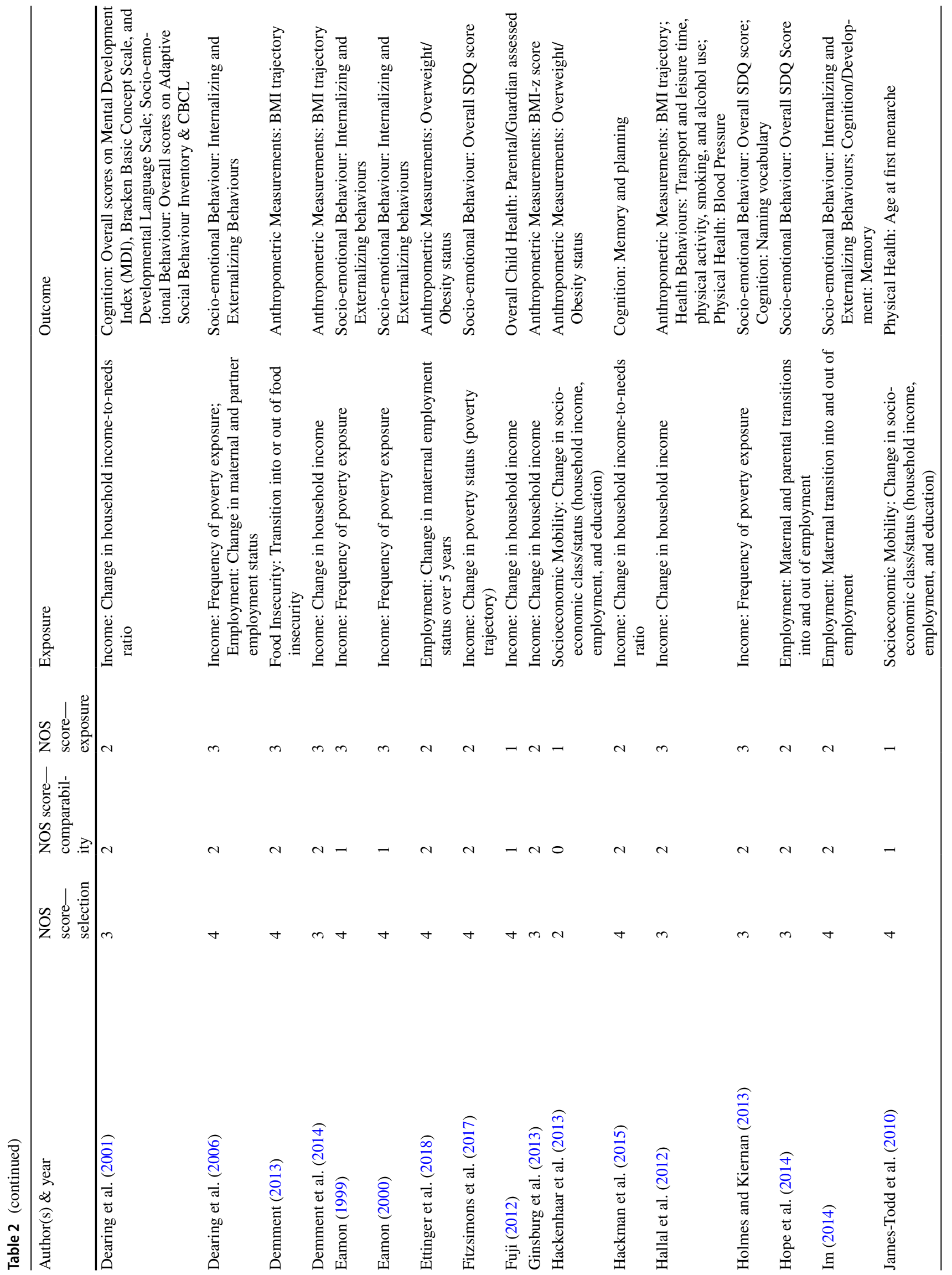




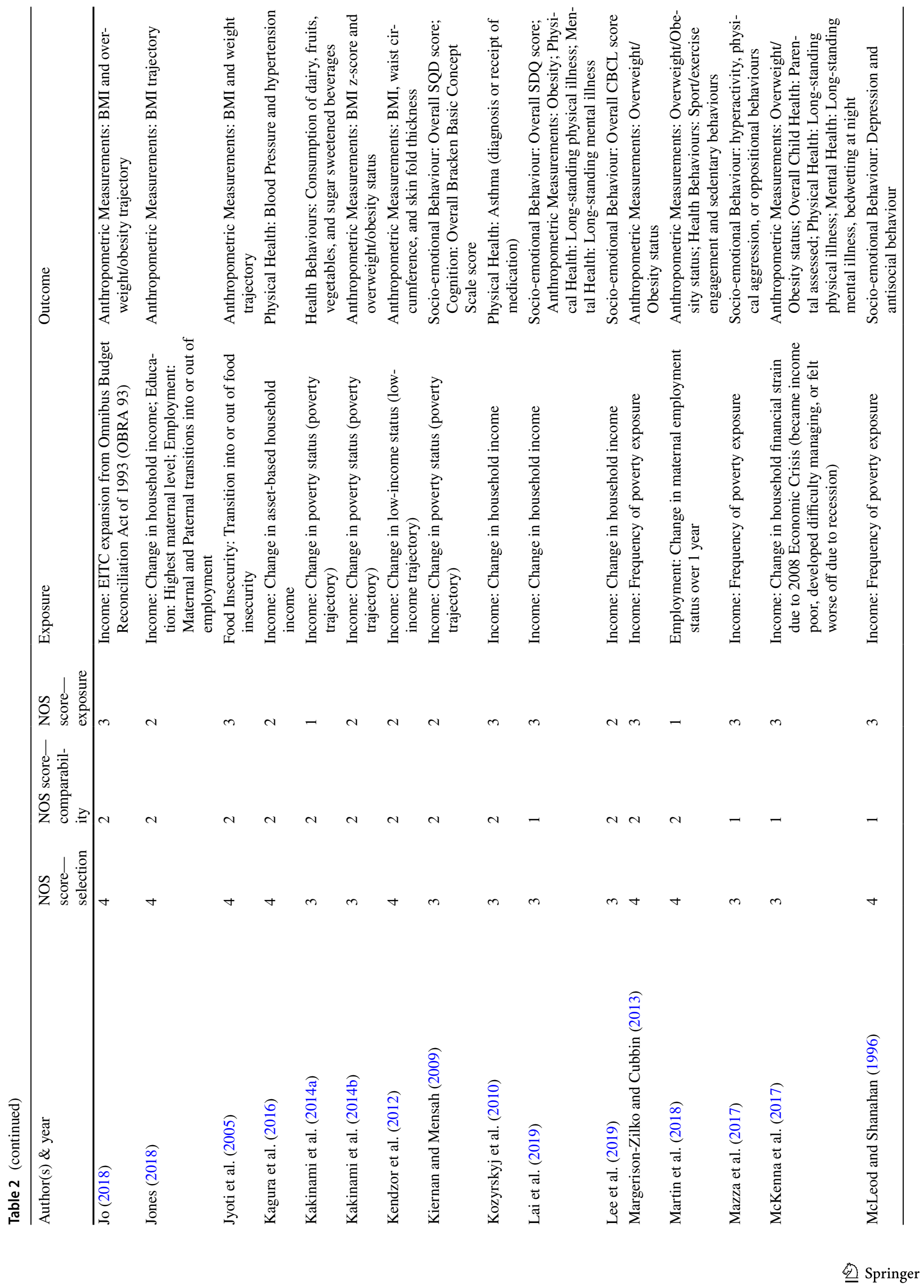




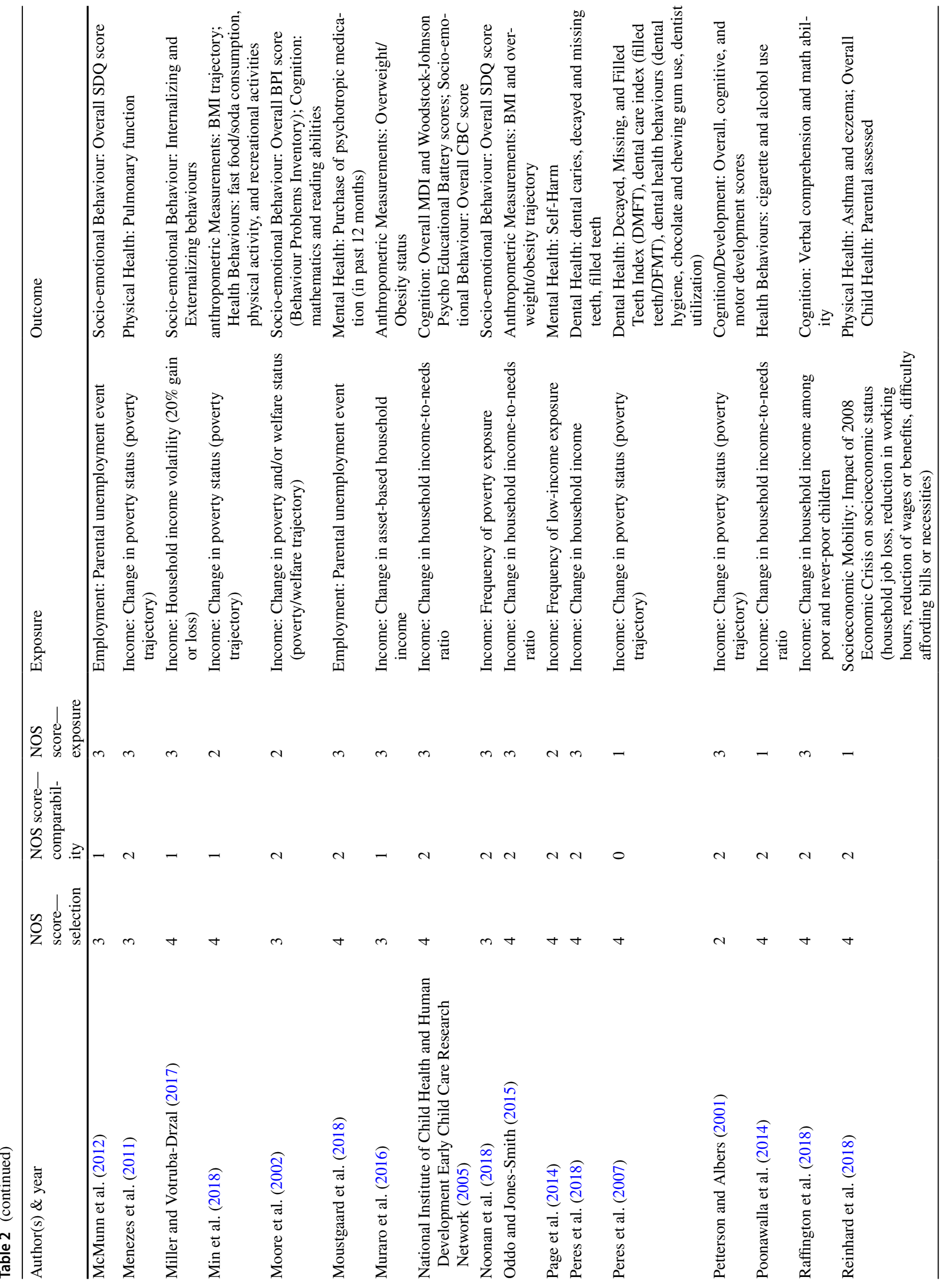




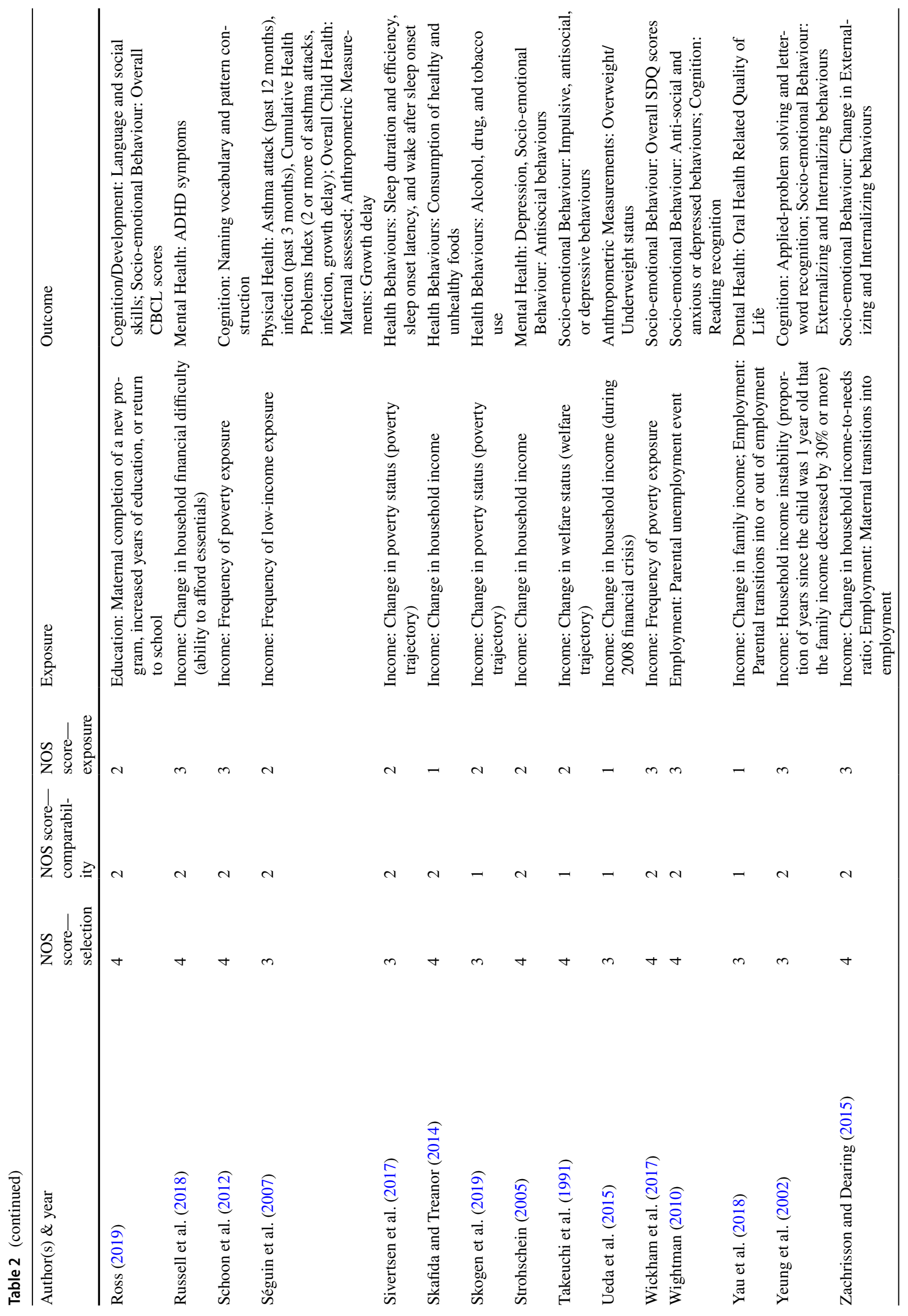


the health outcome prior to the exposure $(n=27,33.8 \%)$. Those studies that received a full score in the Selection category $(n=48,60.0 \%)$ often either started following participants before the health outcome could possibly manifest, controlled for the health outcome at baseline, or measured the continuous change in the health outcome over time (e.g. increase or decrease in BMI-z scores) rather than relying on dichotomous outcomes.

\section{Exposures: Household, Parental, or Familial Socioeconomic Variables}

The socioeconomic variables examined in the included articles were sorted intro five categories: Income $(n=64$, $75.3 \%)$; Employment $(\mathrm{n}=14,16.5 \%)$; Socioeconomic Mobility $(\mathrm{N}=3,3.5 \%)$ meaning composite or general measures of socioeconomic status; Education $(\mathrm{N}=2,2.4 \%)$; and Food Insecurity $(\mathrm{N}=2,2.4 \%)$. These categories were not mutually exclusive, as studies that examined more than one type of socioeconomic exposure were included in both categories, leading to a total of 85 different socioeconomic exposures. Details on the socioeconomic exposures assessed in each article are displayed in Table 2

As noted, over three-quarters of the articles examined Income as an exposure variable. Of these articles, 28 assessed the effect of transitions into poverty/low-income or the association between long-term poverty/low-income trajectories and child/adolescent health. Twenty-three articles were interested in the impact of changes in overall household or parental income over time and seven were interested in changes in household income-to-needs ratios. Another two articles used a material asset-based definition of household income, and two looked at changes in the level of overall household financial difficulties. Finally, two U.S. based studies examined the effect of transitions on or off of welfare, and another U.S. study assessed the impact of increases to household's Earned Income Tax Credit (EITC).

Of the 14 papers that looked at the effect of changes in employment on child health, six were focused only on changes in maternal employment, nine examined the effect of increased work or employment, two included transitions on or off of welfare as part of the employment measure, and all but one assessed the effect of parental job loss. In addition to those articles examining the effect of changes to employment, three articles examined changes in overall socioeconomic mobility: two assessed the effect of socioeconomic class, including employment, income, and education; one looked at the overall impact of changes in family economic circumstances due to the 2008 recession. Two studies examined the effect of a change in parental education, conceptualized as the completion of a new degree, an increase in the parent's years of education, or a return to school. The impact of transitions into or out of food insecurity over time on child BMI/weight was measured in two studies.

\section{Outcomes}

To facilitate analysis, the health outcomes assessed in each study were grouped into eight discrete outcome categories, with several articles examining outcomes in more than one category: Anthropometric Measurements $(n=21)$, specifically weight and BMI; Cognition and Development $(n=15)$; Dental Health $(n=3)$; Health Behaviors $(n=9)$, such as smoking, alcohol/drug use, diet, and exercise; Mental Health $(\mathrm{n}=12)$, including overall mental health assessments and psychiatric conditions; Overall Parent/Guardian Assessed health $(n=6)$; Physical Health Outcomes $(n=11)$, such as asthma and other chronic conditions; and Socio-Emotional Behavior $(\mathrm{n}=30)$, predominantly referring to behaviors assessed with validated screening tools such as the Behavior Problems Index (BPI). Further details on the health outcomes examined in each article are displayed in Table 2. In the following subsections the results are compared thematically based on these outcomes categories.

\section{Anthropometric Measurements}

Of the 21 papers that researched anthropometric measurements, 18 examined the effect of changes in household finances. Distinct geographical patterns emerged from the results of these articles. Among the three studies conducted in Quebec, Canada there was no evidence that household income changes had a unique effect on child/adolescent anthropometric measures not observed among all children exposed to low-income (Côté-Lussier et al. 2015; Kakinami et al. 2014b; Séguin et al. 2007). In comparison, two studies in the U.K. and three Brazilian studies showed mixed evidence, with only one study in each country displaying a unique effect of changing income on child/adolescent BMI (Hackenhaar et al. 2013; Hallal et al. 2012; Lai et al. 2019; McKenna et al. 2017; Muraro et al. 2016). The results of the eight studies in the U.S. were also contradictory, although the majority $(n=6)$ found that either short or longterm decreases in household income were associated with increased subsequent BMI among children and adolescents, and similarly increases in household income were associated with lower subsequent BMI-z scores or weight statuses (Balistreri and Van Hook 2011; Demment et al. 2014; Jo 2018; Jones 2018; Kendzor et al. 2012; Margerison-Zilko and Cubbin 2013; Min et al. 2018; Oddo and Jones-Smith 2015). The former relationship was also found in the one cohort study of Japanese children (Ueda et al. 2015). Meanwhile, the sole South African study found that children whose households saw an increase in income between birth and adolescence 
were actually more likely to be overweight/obese in adolescence (Ginsburg et al. 2013).

Three of the 21 studies evaluating anthropometric measurements assessed the impact of changes to parental employment. Two found that increasing maternal work hours or employment between infancy and childhood/adolescence was associated with increases in child/adolescent BMI (Ettinger et al. 2018; Jones 2018), and one of the two also found paternal employment was associated with decreases in a child's BMI trajectory (Jones 2018). Of the three studies, only one suggested that changes in maternal employment were not associated with overweight/obesity, although this study was restricted to adolescents (Martin et al. 2018). All three studies were conducted in the U.S.

Two U.S. studies evaluated the impact of transition into food insecurity on BMI-z and weight status. One found that becoming food insecure between kindergarten and grade three was associated with larger gains in BMI and weight among male children, but not female children (Jyoti et al. 2005). In contrast, Demment (2013) found that any exposure to food insecurity between birth and age 15 was associated with higher BMI-z scores, compared to food secure children, but there was no long-term protective effect of moving out of food insecurity on BMI-z.

One additional U.S. study assessed the relationship between changes in parental education and BMI. Jones (2018), found that upward transitions in maternal education, when a child was between the ages of two and 18, were associated with linear growth in that child's BMI, that disappeared when controlling for maternal BMI. Meanwhile, upward transitions in paternal education were associated with a linear decrease in a child's BMI.

\section{Cognition and Development}

A total of 15 studies examined the effect of changes in parental or household socioeconomic status on child or adolescent cognition and development. Eleven of the 15 studies examined changes in income: eight in U.S. populations and three in U.K. populations. For the remaining four papers, three analyzed changes in employment and one looked at changes in maternal education, all in the U.S.

Among the 11 articles analyzing changes in income, five found that increased family income between infancy and preschool years (Breidenstine 2004; Dearing et al. 2001; Kiernan and Mensah 2009), or childhood and adolescence (Raffington et al. 2018; NICHHDECCRN 2005) is associated with better cognitive outcomes in the subsequent years, particularly among children whose households were poor at baseline (Breidenstine 2004; Dearing et al. 2001; Raffington et al. 2018). Six studies also provided evidence that long-term decreases in income (Hackman et al. 2015; Moore et al. 2002; Petterson and Albers
2001; NICHHDECCRN 2005) or short-term household income reductions (Holmes and Kiernan 2013; Yeung et al. 2002) between infancy and childhood are associated with worse subsequent cognitive outcomes. Only one study found that household income changes, specifically transient exposure to poverty between birth and 5 years of age, was not associated with subsequent cognitive functioning (Schoon et al. 2012). In summary, 10 out of these 11 studies provided evidence that increasing income trajectories are associated with better overall cognition among children over time while decreasing income trajectories are associated with declines in overall cognition.

Among the three studies examining changes in parental employment, two of the three found no association between changes in maternal employment and child cognition during preschool years (Chase-Lansdale et al. 2003; Im 2014). However, one of these two also found that parental transitions from employment to welfare were subsequently associated with lower reading abilities in adolescence (Chase-Lansdale et al. 2003). In contrast, Wightman (2010) provided evidence that parental job loss events between birth and 9 years of age were associated with lower reading cognition skills, while parental unemployment showed no significant effect on cognition between the ages of 10 and 15. This relationship between parental unemployment and cognition was mostly explained by changes in the home environment, and only somewhat explained by changes in household earning.

One study examined the effect of gains in maternal education on child cognition/development and also found inconsistent results (Ross 2019). Children between 3 and 9 years old whose mothers started with a high school diploma/GED and obtained a certificate or associate degree had higher receptive language scores at 9 years of age, but this relationship only held constant for married mothers and not for single mothers. Meanwhile, the attainment of a high school diploma/GED was only associated with a reduction in child receptive language skills among older mothers. No other differences in outcomes based on maternal age were uncovered. Thus, overall the evidence for the effect of changes in parental education on child/ adolescent cognition and development is inconclusive.

\section{Dental Health and Hygiene}

Only three $(2.8 \%)$ of the included articles examined the effects of changes in household SES on dental health. In two studies using the Pelotas, Brazil Birth Cohort, adolescents who transitioned into or out of poverty had overall worse dental health than persistently non-poor adolescents and better dental health than chronically poor adolescents (Peres et al. 2007, 2018). The third study, based in 
Hong Kong, found that adolescents whose family income decreased between 12 and 15 years of age also experienced a worsening in their oral health, but there was no effect of increases in household income or changes in parental unemployment on adolescent's oral health (Yau et al. 2018). Taken together, the three studies offer some limited evidence of a relationship between income changes and adolescent oral health.

\section{Health Behaviors}

Among the nine articles that assessed the relationship between SES changes and child/adolescent health behaviors, three examined adolescent substance use: one in the U.S., one in Norway, and one in Brazil. Together, the three studies suggest that downward income mobility during childhood may be associated with increased alcohol (Poonawalla et al. 2014), tobacco (Hallal et al. 2012), or drug use (Skogen et al. 2019) in adolescence. The Nordic paper also found that adolescents who experienced upward mobility in childhood reported more tobacco and drug usage (Skogen et al. 2019). In contrast, Hallal et al.'s (2012) study in Brazil found upward mobility to be associated with less tobacco. It should be noted however, that the Nordic study assessed tobacco and drug use at ages 16-19, so a portion of this sample fell outside the target age range of this review (Skogen et al. 2019).

Three of the nine studies assessed the effect of changes in household income over time on children's nutritional behaviors. Results did not show a unique effect of upward or downward income mobility on child/adolescent nutrition in two of these articles, one in the U.K. (Skafida and Treanor 2014) and one in Quebec, Canada (Kakinami et al. 2014a). By comparison, Min et al. (2018) found that children in the U.S. who were recurrently poor between 5 years of age and eighth grade had distinctively worse eating habits than children who were transiently poor or chronically poor. Together, these three studies reveal no generalizable relationship between changes in household income and changes in children's dietary behaviors.

The four papers that assessed the relationship between SES changes and child/adolescent exercise behaviors, also revealed no generalizable patterns. In the U.S., adolescent sedentary behavior was found to increase among children exposed to recurrent poverty (Min et al. 2018) or maternal unemployment (Martin et al. 2018). However, in a Brazilian study, upward income trajectories were associated with an increase in inactive transport use and downward trajectories were associated with the opposite (Hallal et al. 2012). Finally, in Côté-Lussier et al. (2015) study in Quebec, chronic poverty between 5 months and 13 years of age was associated with less physical activity while transitions in and out of poverty during those ages were not.
Only one study, conducted in Norway, examined the relationship between household SES changes and adolescent sleep behaviors. Sivertsen et al. (2017) found that adolescents whose families moved into poverty between 8 and 17 years of age displayed overall worse sleep outcomes while chronically poor adolescents and those who moved out of poverty did not. However, like the other Nordic study this one also assessed the health behavior between the ages of 16 and 19 , partially outside the target age range for this review.

\section{Mental Health}

A total of 12 studies examined the relationship between changes in parental/household SES and child and adolescent mental health outcomes. Nine of these studies assessed the effect of changes in household or parental income, with varying results by geographic region. Two studies conducted in the U.S. demonstrated that improvements in household income between childhood and adolescence were associated with a decreased risk of mental health conditions in adolescence (Costello et al. 2003; Strohschein 2005), and one of the two studies also found evidence for the inverse relationship (Strohschein 2005). However, one of these articles assessed the mental health outcome between ages 13 and 21, partially outside the target age range for this review (Costello et al. 2003). One study in the U.K. found a similar relationship to that observed in the U.S.; improvements in household income during adolescence were associated with a decreased risk of subsequent mental health problems (McKenna et al. 2017). In contrast, the other three U.K. articles all found persistent poverty throughout childhood to be the most important predictor of mental health problems (Lai et al. 2019; Page et al. 2014; Russell et al. 2018). Finally, among the three remaining papers, one South Korean (Choi et al. 2017), one Swedish (Björkenstam et al. 2017), and one Nordic (Bøe et al. 2017), both decreasing and persistently low household income trajectories were associated with an increased subsequent risk of mental health problems among children and adolescents, although the Nordic study assessed the mental health outcomes between 16 and 19 years of age, partially outside the target age range for this review. Together, the results from the U.K., South Korea, Sweden, and Norway do not suggest decreasing household income has any unique effect on child/adolescent mental health not observed in those exposed to chronically low household income.

This review also identified three articles evaluating the relationship between changes in parental employment and child and adolescent mental health outcomes. Chase-Lansdale et al. (2003) found that in the U.S. maternal transitions into employment were associated with decreased psychological distress and anxiety among adolescents, while 
transitions off welfare were associated with decreased drug and alcohol use. Similarly, in an Australian study maternal unemployment was associated with worse subsequent mental health among adolescents, particularly female adolescents, ages 15-20 (Bubonya et al. 2017). In contrast, a Finnish study found that paternal unemployment events, but not maternal unemployment events, lead to an increase in the probability of purchasing psychotropic medications among adolescents ages 13-20 (Moustgaard et al. 2018). Part of the sample population of both the Australian and Finnish paper, however, fell outside the target demographic for this systematic review.

\section{Overall Child/Adolescent Health}

Six of the included articles examined the relationship between changes in household SES and parent/guardian assessed overall child and adolescent health: two in the U.S., two in Canada (Quebec), one in the U.K., and one in Ireland. In general, these studies found that any exposure to negative changes in household SES, including income loss, financial strain, and reductions in parental employment, were associated with worse subsequent parental assessed child health, and positive changes in household SES were associated with the opposite (Chatterji et al. 2013; Fuji 2012; McKenna et al. 2017; Reinhard et al. 2018; Séguin et al. 2007). The exception was one paper from Quebec that found children exposed to transient poverty between 5 and 41 months were not more likely to be rated as less healthy by their mothers than never poor children (Béatrice et al. 2012), however the other paper from Quebec found the exact opposite result among children in the exact same age range (Séguin et al. 2007).

One of the articles explored the pathways through which changes in parental/household SES affect overall child health in more detail. In a U.S cohort of children 4-13 years old, Fuji (2012) found that an involuntary job loss by the household head was associated with a negative effect on child health for younger children. However, this relationship was not explained by the negative income growth following the job loss and decreases in income due to job loss were not more detrimental to child health than income losses from other sources. Conversely, negative income growth in the context of a parental disability event was associated with a more pronounced negative effect on the health of younger children than other household income losses.

\section{Physical Health}

All 11 of the included articles that assessed physical health outcomes analyzed changes in income or overall socioeconomic mobility as the exposure. A significant relationship between changes in SES and a diverse set of child/adolescent physical health outcomes was found in seven of these 11 studies. Among a U.S. cohort of female children, JamesTodd et al. (2010) found that downward socioeconomic mobility between birth and age seven was associated with a decline in the age at menarche. Similarly, two studies in the U.K. showed that children exposed to negative changes in household income experienced worse physical health overtime (Lai et al. 2019; McKenna et al. 2017), particularly compared to children exposed to improvements in household income (Lai et al. 2019). A relationship between SES changes and asthma was also found in two articles. The first, in Australia, demonstrated that increasing household income between birth to age 14 was associated with a decreased risk of asthma at age 14 for male children only (Kozyrskyj et al. 2010). The second study, based on an Irish cohort, provided evidence that only reductions in welfare benefits, and no other negative changes in household employment or financial situation, between 9 months and 5 years of age were associated with an increased risk of reporting asthma and atopy symptoms at 5 years (Reinhard et al. 2018). Related to these two articles, Menezes et al. (2011), found in a Brazilian cohort that income trajectory from birth to adolescence was associated with lung function, although this relationship was largely mediated through height, particularly for boys. Finally, Kagura et al.'s (2016) study in South Africa demonstrated that upward socioeconomic mobility between birth and 16 years was associated with lower systolic blood pressure, but no other measurements of blood pressure, at age 18 compared to chronically low SES profiles.

Four of the 11 studies of physical health outcomes, however, did not find changes in income to be significantly associated with child/adolescent health outcomes. Two studies in Quebec found that only chronic income, and not transient income, between 5 and 41 months of age was associated with asthma and cumulative health problems (Béatrice et al. 2012; Séguin et al. 2007), contradicting the results of Kozyrskyj et al. (2010) and Reinhard et al. (2018). The results presented by Hallal et al. (2012) from the Pelotas, Brazil Birth Cohort also contradict the results of Kagura et al. (2016), as they show no relationship between income trajectory and blood pressure. Finally, one U.S. study, by Chen et al. (2007), found that lifetime income variability was not an important predictor of activity limitations or chronic health problems, and that children who moved into lowincome during childhood still had better health outcomes than chronically poor children.

\section{Socio-emotional Behavior}

A total of 30 papers examined the effect of SES changes on children's and adolescents' socio-emotional behavior. Of these papers, 24 examined the impact of changes in household income, seven examined employment, and one examined education. 
The overwhelming majority of the articles that examined the effect of income changes were based on samples in the U.S. $(n=12)$ or the U.K. $(n=7)$. There were also two studies conducted in Norway, and one each in Brazil, Australia, and South Korea. Among these studies, 13 found a unique effect of changing income status on the socio-emotional behavior outcomes of children and adolescents. Nine articles reported that increases in income were associated with fewer subsequent behavioral problems, or, inversely, that decreases in income were associated with subsequent increases in children's behavioral problems (Dearing et al. 2001, 2006; Lai et al. 2019; Lee et al. 2019; McMunn et al. 2012; Miller and Votruba-Drzal 2017; Strohschein 2005; Yeung et al. 2002; Wickham et al. 2017; Zachrisson and Dearing 2015). In four of these studies, parental mental health, parenting practices, and/or childcare arrangements acted as important mediators in the relationship between household income changes and child behavioral outcomes (Lee et al. 2019; Wickham et al. 2017; Yeung et al. 2002; Zachrisson and Dearing 2015). Two unique studies on welfare entry and exit also found that transitions from poverty to welfare between childhood and early adolescence were associated with worse behavioral outcomes, and transitions from welfare to poverty were associated with the inverse (Moore et al. 2002; Takeuchi et al. 1991). Finally, one outlying study found that adolescents who moved into poverty had worse hyper and better peer scores on the Strength and Difficulties Questionnaire (SDQ), compared to chronically poor children, while moving out of poverty was associated with the opposite. However, the sample for this study included adolescents from 16 to 19 years old, slightly outside the target age for this review (Bøe et al. 2017).

In contrast to the evidence of the previous 13 articles, 11 studies did not provide evidence for a unique effect of income changes on child and adolescent behavioral outcomes. In five of these studies, both chronic poverty and long or short-term transitions into poverty were associated with greater subsequent behavioral problems (Anselmi et al. 2012; Bor et al. 1997; Fitzsimons et al. 2017; NICHHDECCRN 2005; Kiernan and Mensah 2009). Meanwhile five papers found that chronic or accumulated poverty, rather than transient poverty, was associated with increased behavioral problems over time (Eamon 1999, 2000; Mazza et al. 2017; McLeod and Shanahan 1996; Noonan et al. 2018). Finally, one study provided no evidence for any association between poverty exposure and subsequent behavioral problems (Holmes and Kiernan 2013).

Eight articles examined the effect of changes in parental employment on children's behavioral outcomes. One study found that any maternal transition in or out of employment was associated with more subsequent behavioral problems, with transitions into employment associated with more externalizing problems than transitions out of employment (Im 2014). Similarly, Dearing et al. (2006) showed that increases in maternal employment were associated with increased externalizing problems, specifically for chronically poor children, although increases in partner employment hours were associated with decreased internalizing problems. Comparatively, in three studies, maternal transitions into employment were not associated with more behavioral problems or were associated with fewer subsequent problems (Chase-Lansdale et al. 2003; Hope et al. 2014; Zachrisson and Dearing 2015). Three articles also reported that transitions into maternal and/or paternal unemployment were associated with an increased risk of developing socioemotional behavior problems in childhood (Chase-Lansdale et al. 2011; Hope et al. 2014; Wightman 2010). However, the sample population of one of these studies, Chase-Lansdale et al. (2011), fell partially outside the target age of this review. Finally, one of the eight studies found no association between brief parental unemployment and subsequent behavioral outcomes (McMunn et al. 2012).

The one study that examined the effect of changes in maternal education on children's behavioral outcomes reported mixed results. The children of mothers who obtained a high school diploma/GED had lower internalizing behavior problems, but the attainment of a certificate/ associated degree was associated with an improvement in behavior only for children whose mothers were not married to the child's father (Ross 2019). There were also no discernable patterns when results were stratified by income groups.

\section{Discussion}

Children and adolescents are acutely vulnerable to the influence of SES on health outcomes (Condliffe and Link 2008). While the long-term effects of low-SES on children's health are well established (Currie and Stabile 2003), less emphasis has been placed on understanding the impact of changes in SES on children's health. This review provides the first synthesis to date of literature examining the effects of changes in family, parental, or household SES on the physical, mental, and overall health of children and adolescents. Overall, there was no consistently observed pattern in the impact of changes in SES on each health outcome, and thus no broad conclusions can be made regarding a universal relationship between socioeconomic changes and child/adolescent health. Instead, the overall effect of the different socioeconomic variables (income/SES mobility, employment, food security, and education) on each health outcome are synthesized and compared below, and insights for further research and policy development are highlighted. 


\section{Income and Socioeconomic Mobility}

Of the 81 studies included in this review, 64 (80\%) examined the effect of changes in income on one or more of the eight possible categories of outcome. There were also three (3.8\%) studies that examined the effect of overall socioeconomic mobility on child or adolescent health (Hackenhaar et al. 2013; James-Todd et al. 2010; Reinhard et al. 2018). The results of the latter three followed similar patterns as the results from the studies of income, so the two exposures are discussed together. In four of the eight outcome categories, evidence from the included articles revealed a rather consistent pattern for the effect of changes in parental/household income on child/adolescent health: Cognition and Development, Dental Health, Overall Parent-Reported Health, and Physical Health Conditions.

The research examining Cognition and Development, displayed consistent evidence that increasing household/parental income trajectories over time were associated with better overall cognition while the inverse was true for decreasing income trajectories (see e.g. Breidenstine 2004; Dearing et al. 2001; Kiernan and Mensah 2009; Moore et al. 2002; NICHHDECCRN 2005). However, the effect of abrupt or transient changes in income was less conclusive, as two of the three papers found that abrupt negative changes in income had a corresponding negative effect on child/adolescent cognition and development (Holmes and Kiernan 2013; Yeung et al. 2002), and one study did not (Schoon et al. 2012). Taken together though, evidence from 10 of these 11 studies suggests that negative changes in income are consistently associated with worse subsequent child cognition, while positive changes are associated with improved cognition and development.

Similar to the results for Cognition and Development, all three studies that evaluated the effect of income changes on Dental Health provided at least limited evidence that negative income changes in childhood are associated with worse subsequent adolescent oral health, or inversely that positive income changes were associated with ameliorated oral health (Peres et al. 2007, 2018; Yau et al. 2018). These preliminary results could have interesting implications for understanding public oral health trends, and more research on this topic is warranted to extrapolate on these findings. There should also be a concerted effort to assess the generalizability of these findings in geographically diverse samples, since the current three studies were restricted to Pelotas, Brazil and Hong Kong, China.

There was also a clear pattern in the effect of changes in household income or general socioeconomic mobility on parent/guardian assessed overall child/adolescent health. Evidence from five of the six papers examining this relationship supports that exposure to negative changes in household SES are associated with subsequent reductions in children's overall parent-assessed health (Chatterji et al. 2013; Fuji 2012; McKenna et al. 2017; Reinhard et al. 2018; Séguin et al. 2007).

Comparably, the majority $(n=7)$ of the 11 studies on the effect of income/overall socioeconomic mobility on child/ adolescent physical health found that downward income/SES trajectories were associated with adverse subsequent physical health outcomes while upward trajectories were associated with the opposite (see, e.g. James-Todd et al. 2010; Kozyrskyj et al. 2010; Lai et al. 2019; McKenna et al. 2017). However, the remaining four studies found no evidence that downward socioeconomic mobility was linked to worsening physical health outcomes (Béatrice et al. 2012; Chen et al. 2007; Hallal et al. 2012; Séguin et al. 2007). Therefore, additional research is needed to support the strength of the relationship between income mobility and child/adolescent physical health. Furthermore, the 11 studies examined a diverse set of physical health outcomes, with some outcomes, such as age at menarche and blood pressure, assessed by only one or two studies, respectively. Expanding the corpus of research could help establish the effect of income changes on each individual health condition/outcome.

In two of the outcome categories, Anthropometric Measurements and Mental Health Outcomes, the results were mixed with clearer patterns emerging when studies were stratified by geography. For Anthropometric Measurements, the effect of income changes varied substantially by geographical region. There was no evidence of a relationship between income changes and anthropometric outcomes in Quebec, Canada (Côté-Lussier et al. 2015; Kakinami et al. 2014b; Séguin et al. 2007), mixed evidence in the U.K. (Lai et al. 2019; McKenna et al. 2017), and mixed evidence in the U.S. with the majority of studies suggesting a significant relationship between changes in income and anthropometric outcomes (see, e.g., Demment et al. 2014; Jo 2018; Jones 2018; Kendzor et al. 2012). Where a relationship existed in the aforementioned studies, negative changes in income were generally associated with increased subsequent BMI/ obesity, with the inverse also being true. In contrast, among the four studies based in the global south the evidence either showed no relationship (Hackenhaar et al. 2013; Muraro et al. 2016) or displayed the opposite relationship, with increased income associated with increasing BMI (Ginsburg et al. 2013; Hallal et al. 2012). Thus, there is a substantial need for more research on this subject with a greater geographical distribution to draw consistent conclusions and uncover the socioeconomic conditions or policies underpinning these geographical differences.

A similar geographic variation was found among the nine studies on the effect of changing income on mental health outcomes. The two studies in the U.S. suggested improvements in income during childhood were associated with decreased mental health issues and adolescence 
and decreases in household income were associated with the opposite (Costello et al. 2003; Strohschein 2005). By contrast, persistent childhood poverty was found to be the most important predictor of adolescent mental health in three of four studies published in the U.K. (Lai et al. 2019; McKenna et al. 2017; Page et al. 2014; Russell et al. 2018). In the three remaining papers, based in South Korea, Sweden, and Norway, both decreasing income and persistently low income were associated with subsequent mental health issues (Björkenstam et al. 2017; Bøe et al. 2017; Choi et al. 2017). Taken together, these studies suggest that decreases in household income do not have a unique effect on child/ adolescent mental health beyond the effect of general exposure to low-income. The exception may be in the U.S., and further studies should be conducted on this topic, both in the U.S. and abroad, to determine if this relationship is indeed uniquely observed in U.S. populations.

In the remaining two categories, Health Behaviors and Socio-emotional Behavior, the results are simply inconclusive. For health behaviors, this inconclusiveness is due to distinctly different result patterns for each type of health behavior. For example, there was some evidence that downward income mobility during childhood may be associated with increased substance use in adolescence, although the particular substance that increased differed in all three geographically diverse samples (Hallal et al. 2012; Poonawalla et al. 2014; Skogen et al. 2019). Meanwhile, there was no evidence of an effect of long-term income trajectories on nutritional or exercise behaviors (Kakinami et al. 2014a; Skafida and Treanor 2014), although one study suggested that recurrent poverty, but not chronic or transient poverty, was associated with worse subsequent exercise and nutritional behaviors (Min et al. 2018). Finally, one Nordic study found that transitioning into poverty was associated with worse subsequent sleep outcomes in adolescence (Sivertsen et al. 2017). Overall, the current body of research suggests an interesting association between income changes and subsequent adolescent substance use, with possible regional variation, as well as subsequent sleep patterns, both of which should be expanded upon further in future research. The limited literature on the effect of income changes on nutrition and exercise behaviors do not support a consistent relationship, and should also be expanded upon, to strengthen the evidence base.

The reviewed studies that assessed the effect of income changes on socio-emotional behavior also did not display a consistent relationship. Thirteen of the 24 articles in this category found that long-term or transient losses of income were associated with worse subsequent socio-emotional behavior, but nine studies found no unique effect of changes in income on child and adolescent behavioral outcomes (see e.g. Lai et al. 2019; Mazza et al. 2017; Miller and VotrubaDrzal 2017; Noonan et al. 2018; Yeung et al. 2002). Thus, further research on this topic is needed to clarify the relationship between income changes and behavior.

One possible area of further research could be to expand upon the finding that the effects of transitions into poverty may be more perceptible at later ages; specifically that persistent poverty between birth and childhood is the most important predictor of behavioral problems at age five, while transitions into poverty are more important at age 11 (Fitzsimons et al. 2017). These results are based on evidence from a U.K cohort, so replicating the study in different countries could help determine if clearer patterns are elucidated at different ages. This area of research has the potential to reconcile some of the disagreement in the current literature, if the unique effect of income changes on child health outcomes, particularly behavioral outcomes, is found to be more perceptible at later ages.

An alternative method for reconciling contradictory results in the current literature is to change the way poverty exposures are conceptualized. For example, two studies found unique results when chronic poverty was used as the reference category to assess the effect of income changes, as opposed to the typical reference category of consistently non-poor (Bøe et al. 2017; Eamon 2000). Therefore, the unique effects of changes in income on health outcomes may be better elucidated when income is operationalized in a way that compares positive income changes to chronic poverty. Similarly, two studies of cognition and socio-emotional behaviors found that the positive effects of increases in household income were accentuated among chronically poor children and diminished, or absent, among non-poor children (Breidenstine 2004; Dearing et al. 2001). Effectively, these papers uncovered a more nuanced relationship between changing income and child health by assessing the effect of income changes among chronically poor and non-poor children separately. The typical operationalization of income in this review compared children in several income trajectories, usually chronic poor, transition into poverty, transition out of poverty, or transient poverty, to chronically non-poor children. Future research could expand off of these four studies to re-operationalize income in a way that elucidates a more nuanced relationship between changes in household income and child health.

Another useful pathway for future research could be to build upon the finding that negative income growth due to job loss did not have a more negative effect on children's overall health than income loss due to other sources, while the effects of income due to parental disability on child health were more pronounced (Fuji 2012). This was the only study identified that explicitly compared the effects of different sources of income loss, but the results bear replicating in different populations and with different health outcomes as they could have clear public health and policy implications. 
There were also several studies included in this review that found parental mental health, parenting practices, and/or childcare arrangements to be important mediators of the relationship between income changes and child cognition and behavioral outcomes (see e.g., Holmes and Kiernan 2013; Lee et al. 2019; NICHHDECCRN 2005; Yeung et al. 2002; Zachrisson and Dearing 2015). These results should also be replicated and expanded to other geographical populations and different health outcomes, as they could potentially offer a valuable key to understanding the mechanisms linking income changes to child health outcomes. This knowledge could in turn inform policy approaches aimed at mitigating the detrimental effects of changing income on children's health.

\section{Employment}

Fourteen of the included studies assessed the effect of changes in parental employment on the health of children or adolescents. Of these 14 studies, three (21.4\%) examined anthropometric measurements, two (14.3\%) examined cognition or development, one (7.1\%) examined health behaviors, one $(7.1 \%)$ examined dental health, three $(21.4 .0 \%)$ examined mental health outcomes, and eight $(57.1 \%)$ examined behavioral outcomes. The unique aspect of parental employment, as an exposure, is that two prevalent and contradictory mechanisms are proposed to explain how parental employment affects children's health. The first mechanism follows the direction observed in most studies of income, with unemployment viewed as a negative shock to a household, in terms of resources and health, and therefore increased employment serves as a net benefit to a house (see e.g. Bubonya et al. 2017; Moustgaard et al. 2018). In contrast, there is also the theory that increased maternal employment reduces the quality of childcare and maternal-child interactions, leading to worsened subsequent child health (see e.g. Ettinger et al. 2018; Im 2014).

Results from the three studies assessing mental health outcomes and the one study assessing adolescent sedentary health behaviors support the first mechanism. There is a generally consistent pattern in these papers that parental transitions into employment are associated with decreased mental health issues and improved health behaviors while transitions into unemployment are associated with the inverse (Bubonya et al. 2017; Chase-Lansdale et al. 2003; Martin et al. 2018; Moustgaard et al. 2018). However, there was variation between these studies in which parent's employment, mother's or father's, was significantly associated with child/adolescent mental health.

In the remaining four outcome categories, anthropometric measurements, socio-emotional behavior, dental health, and cognition/development, the relationship between employment transitions and child health is less clear. The limited evidence from the three studies evaluating the effect of parental employment on anthropometric measurements seems to suggest that increased maternal employment is associated with subsequent increases in BMI, supporting the second mechanism, while increased paternal employment is associated with decreases in BMI (Ettinger et al. 2018; Jones 2018; Martin et al. 2018). Similarly, two studies on children's socio-emotional behavior found that increased maternal employment was associated with subsequent behavioral problems (Im 2014; Dearing et al. 2006). However, four studies also found no relationship or the opposite relationship between increased maternal employment and child behavior (Chase-Lansdale et al. 2003, 2011; Hope et al. 2014; Zachrisson and Dearing 2015). Furthermore, two studies of general parental employment, not separated by gender, found unemployment events to be associated with increased child/adolescent behavioral problems (Hope et al. 2014; Wightman 2010), although another similar study did not find this relationship (McMunn et al. 2012). Yau et al. (2018) also found no relationship between changes in parental employment and adolescent's oral health. Finally, in the Cognition and Development category, two studies found no effect of parental employment (Chase-Lansdale et al. 2003; Im 2014), while one study found that the negative effect of a parental job loss on subsequent cognition changed and decreased as children aged (Wightman 2010).

Overall, the body of literature on the effect of changing employment on subsequent child/adolescent health is inconclusive, specifically in regard to the effects of increased maternal employment on child/adolescent health. There is a definite need for further research on this topic to better clarify the mechanisms underpinning the relationship between parental employment changes and child health, especially given that only $13(16.25 \%)$ of the 80 studies included in this review examined employment as an exposure. One useful area for further research would be to replicate the finding that the effect of unemployment on child health outcomes changes over time (Wightman 2010). This approach could help reconcile some of the current disagreements in the literature, as most of the included studies focused on a particular, narrow age group (see Table 1). It should also be noted that while the mechanism underlying the relationship between parental employment, particularly maternal employment, and child health is still unclear, eight of the 12 studies found some evidence that decreases in parental employment had a negative effect on various child health outcomes. This evidence underscores the importance, from both a research and a policy perspective, of paying attention to the potential detrimental effects of unemployment events on the children of the unemployed (Bubonya et al. 2017). 


\section{Other Measures: Food Security, Education, and Socioeconomic Mobility}

Changes in parental education and household food security were each only examined as exposures in two papers included in this review. The absence of studies assessing these exposures makes it difficult to draw definitive conclusions about how they relate to child and adolescent health. Both of the studies that examined the effect of changes in household food security were interested in anthropometric outcomes. The results of these two studies are inconclusive as one found the protective effect of becoming food secure disappears after infancy (Demment 2013), while the other found that becoming food insecure was associated with a larger subsequent weight gain among children compared to becoming food secure, but did not compare food insecurity to persistent food security (Jyoti et al. 2005). One of the studies on parental education also assessed BMI as an outcome and found that increased maternal education was not associated with subsequent weight gain while gains in paternal education were associated with decreases in weight (Jones 2018). Meanwhile the other study on education found a very complex and inconsistent pattern between different educational attainments and subsequent changes in children's behavior and cognition (Ross 2019).

There were also three papers included in this review that examined composite measures of socioeconomic mobility as the exposure (Hackenhaar et al. 2013; James-Todd et al. 2010; Reinhard et al. 2018). The results of these three studies were discussed with the results of income, but it bears mentioning that this was another category of exposure that has been under-studied in the literature.

The current review includes interesting, while inconclusive, results that link changes in all three of these socioeconomic exposures, food security, education, and socioeconomic mobility, to child and adolescent health outcomes. All measures of socioeconomic status have important limitations. For example, measures of current income do not account for important assets or access to health/social services, and many are not adjusted to geographical variations in the availability, quality, and price of goods and services (Shavers 2007). The overrepresentation of studies using income as the socioeconomic exposure in this review is a definite limitation in the current understanding of the effect of changes in SES on child health. Future research on this topic should therefore seek to move beyond income and explore the effect of changes in other measures of SES, including employment, education, and composite or assetbased measures.

\section{Inclusion of Adolescents over Age Eighteen}

Defining adolescence is difficult as conceptions of adolescence have evolved over time and change depending on the physiological, cultural, or legal framework that underpins them. In this review, the target sample was children or adolescents 18 years of age or younger, as 18 coincides with the age of majority in many jurisdictions as well as the conclusion of secondary education (Curtis 2015). However, 8 studies were identified that included adolescents over 18 years of age and did not separate these older adolescents from respondents 18 years of age or younger. The decision was made to include these eight studies due to imprecision inherent in defining adolescence as well as concerns that excluding them could also entail removing findings that pertained to adolescents under age 18 . However, it is worth examining what influence the inclusion of these eight articles had on the results.

Five of the eight articles examined the relationship between changes in income and subsequent child/adolescent health outcomes. Among those five studies, two provided evidence of a significant relationship between changes in income and the subsequent health behaviors of adolescents (Sivertsen et al. 2017; Skogen et al. 2019). Exclusion of either article from the review would not significantly alter the overall conclusion that the evidence linking income changes to health behaviors is inconclusive, as inconsistent results were observed for each category of health behavior and these two studies each evaluated a different type of health behavior. Similarly, Chatterji et al. (2013) was one of five articles that found decreased income to be associated with subsequent decreased overall health in children and adolescents, a relationship that was opposed by only one study. Exclusion of Chatterji et al. (2013) would therefore not impact the overall pattern that was observed between income and overall health. In contrast, Costello et al. (2003) was one of only two studies in the U.S. to show a unique effect of changing income on mental health outcomes, so removing this study due the inclusion of respondents over age 18 would weaken the suggested geographic pattern. Overall though, the majority of studies that evaluated the relationship between income changes and mental health did not find evidence of a unique relationship between the two, including Bøe et al. (2017), which also included respondents over age 18. Inclusion of these latter two studies, therefore, did not impact the overall conclusion that more evidence would be needed to establish and clarify regional patterns in the relationship between income changes and subsequent child/adolescent mental health outcomes. In summary, removal of the five articles that assessed the relationship between income changes and child health would not change the overall patterns observed in this review. 
Three of the eight articles that included respondents over 18 years of age examined the impact of changes in employment on child/adolescent health. Chase-Lansdale et al. (2011) was one of four studies that did not find increased maternal employment to be associated with subsequent increased behavioral problems, so the individual inclusion of this study did not significantly alter the conclusions of this review. Meanwhile, Bubonya et al. (2017) and Moustgaard et al. (2018) were two of only three studies that suggested parental unemployment events have a negative impact on subsequent child/adolescent mental health outcomes. Exclusion of these latter two studies would significantly reduce the evidence supporting the negative relationship between parental unemployment events on child/adolescent mental health, although no studies were identified that refuted this relationship. If all three studies were removed, there would remain five studies that found decreases in parental employment to be associated with negative changes in child/adolescent health and four studies that did not, lessoning the consensus on the relationship between parental employment changes and child health outcomes.

\section{Limitations}

In addition to the overrepresentation of income as an exposure, an additional limitation of the research included in this review is the distinct overrepresentation of North American and European studies $(\mathrm{N}=64,80 \%)$, particularly U.S. studies $(\mathrm{N}=38,47.5 \%)$. There were often few, if any, articles from outside North America and Europe that investigated trends observed in those two continents, limiting the generalizability of certain patterns in the literature. In contrast, there were also examples where some health outcomes were only examined outside of North America, such as dental health, which again limits generalizability. Research in certain countries was also limited to specific geographical areas, such as the six Canadian studies included in this review, which all came from Quebec. The results in this review, and the information summarized in Table 1, should facilitate the identification of geographical weaknesses in the current literature, and future research should try to replicate existing studies in new, more diverse geographies.

It was beyond the scope of this review to conduct a thorough vetting and evaluation of article methods, as the principal goal of this project was to provide the first ever review summarizing and synthesizing the state of the literature on the effect of changes in household SES on child and adolescent health. However, a brief evaluation of bias using the NOS was performed, and detailed results of this evaluation are displayed in Table 2. Overall, the papers included in this review displayed a low-level of bias, with $83.8 \%$ of the 80 studies scoring a 7 or higher, out of 9 , on the NOS scale. The lowest score, three, was found in only one study (Hackenhaar et al. 2013). Based on the bias analysis, the three most significant areas for improvement were using reliable methods to account for survey attrition, controlling for both SES and health confounding variables, and ensuring that the sample did not have the health outcome prior to exposure.

Finally, in terms of the limitations of this review, the most significant is the possibility that publication bias influenced the observed results and patterns. The impact of publication bias on systematic reviews varies significantly between research fields. For example, a recent review found evidence of only mild publication bias in the fields of psychology and medicine, while another found that strong results in the social sciences were significantly more likely to be written up and published than weak results (Franco et al. 2014; Van Aert et al. 2019). Given the heterogeneous nature of this systematic review, which straddles multiple research fields, it was not possible to perform the types of bias-adjustment analyses that are used in meta-analyses. Therefore, the impact of publication bias on the results of this review are unknown. This limitation was likely somewhat mitigated, however, by a comprehensive search of gray literature, which includes searching for reports and findings not published in academic journals, as well as the inclusion of dissertations that were not subsequently published in academic journals. Another limitation relates to the search terms used in this review. Firstly, it is possible that the search terms used were more biased towards income and employment than to other socioeconomic exposures, as these two socioeconomic exposures were specifically referenced in the search terms. Secondly, the concept of "change" was also difficult to capture in the search terms; studies often examined socioeconomic transitions alongside more stable socioeconomic trajectories and so the analysis of a change in socioeconomic status was not always clear from the abstract and title. These limitations were partially accounted for, however, by the thorough search of gray literature and a hand search of included reference lists. Search terms related to health were also explicitly not included in the search strategy to ensure that the results were not biased in terms of outcomes.

\section{Conclusion}

Understanding the unique impact of changes in SES on child and adolescent health, as compared to the impact of chronic exposure to a specific socioeconomic level, has important policy and research implications. To synthesize the current literature on this topic, this article systematically reviewed the effect of changes in household or parental SES on the physical, mental, and overall health of children and adolescents. The results of this review demonstrated consistent patterns in the effect of changes in household income on child and adolescent cognitive/developmental outcomes, dental 
health, physical health, and overall guardian-assessed health. This review also found contrasting results on the relationship between changes in parental employment status and child/ adolescent health outcomes; although several studies found that decreases in paternal or combined parental employment were associated with worsened subsequent child health outcomes, other studies found the inverse relationship when examining maternal employment. Measures of income and employment made up the vast majority of exposures studied in this review, suggesting the need for future research to explore and compare more diverse types of socioeconomic exposures. Given that every measure of socioeconomic status has limitations, it is important that future research into the effect of SES changes on child and adolescent health examines a larger variety of socioeconomic variables. Overall, though, the literature in this review provides at least partial evidence of a relationship between changing household SES and each category of child and adolescent health outcomes, and in several cases the evidence supported strong relationships between the two. To strengthen the current literature and resolve inconsistencies, researchers should seek to explore a wider variety of socioeconomic exposures, replicate current geographically isolated results in diverse geographies, and explore the pathways linking changes in SES to child and adolescent health.

Supplementary Information The online version contains supplementary material available at https://doi.org/10.1007/s40894-021-00151-8.

Acknowledgements The authors would like to thank Professor Kevin Gorey for the initial inspiration to conduct this systematic review. We are thankful for funding from the Schulich-UWindsor Opportunities for Research Excellence Program (SWORP). This work was also supported by Mitacs through the Mitacs Research Training Award. Neither program had any role in the study design, the collection or analysis of data, the writing of this article, or in the decision to submit for publication.

Preregistration The complete protocol for this review was preregistered before completion of initial study screening on PROSPERO, ID CRD42020160653.

Author Contributions ARL conceived of the study, developed the methodology, conducted the formal analysis and investigation, and wrote the original draft; SM assisted with the investigation, validation of results, and the editing and revision process; SAB helped with the conceptualization of the study, aided in the validation of results, and assisted with editing and revision; RR was involved in the development of the methodology and responsible for data curation. All authors reviewed and approved the final version of the manuscript.

Funding This research is supported by the Schulich-UWindsor Opportunities for Research Excellence Program (SWORP), a partnership between Western University's Schulich School of Medicine and Dentistry and the University of Windsor. This work was also supported by Mitacs through the Mitacs Research Training Award.

\section{Compliance with Ethical Standards}

Conflict of interest The authors declare that they have no conflict of interest.

\section{References}

Anselmi, L., Menezes, A. M., Hallal, P. C., Wehrmeister, F., Gonçalves, H., Barros, F. C., et al. (2012). Socioeconomic changes and adolescent psychopathology in a Brazilian birth cohort study. Journal of Adolescent Health, 51, S5-S10.

Balistreri, K. S., \& Van Hook, J. (2011). Trajectories of overweight among US school children: A focus on social and economic characteristics. Maternal and Child Health Journal, 15, 610-619.

Beale, N., \& Nethercott, S. (1985). Job-loss and family morbidity: A study of a factory closure. The Journal of the Royal College of General Practitioners, 35, 510-514.

Béatrice, N., Lise, G., Victoria, Z. M., \& Louise, S. (2012). Longitudinal patterns of poverty and health in early childhood: Exploring the influence of concurrent, previous, and cumulative poverty on child health outcomes. BMC Pediatrics, 12, 141.

Björkenstam, E., Cheng, S., Burström, B., Pebley, A. R., Björkenstam, C., \& Kosidou, K. (2017). Association between income trajectories in childhood and psychiatric disorder: A Swedish population-based study. Journal of Epidemiology and Community Health, 71, 648-654.

Bøe, T., Skogen, J. C., Sivertsen, B., Hysing, M., Petrie, K. J., Dearing, E., \& Zachrisson, H. D. (2017). Economic volatility in childhood and subsequent adolescent mental health problems: A longitudinal population-based study of adolescents. British Medical Journal Open, 7, e017030.

Bor, W., Najman, J. M., Andersen, M. J., O'callaghan, M., Williams, G. M., \& Behrens, B. C. (1997). The relationship between low family income and psychological disturbance in young children: An Australian longitudinal study. Australian and New Zealand Journal of Psychiatry, 31, 664-675.

Bramer, W. M., Giustini, D., de Jonge, G. B., Holland, L., \& Bekhuis, T. (2016). De-duplication of database search results for systematic reviews in EndNote. Journal of the Medical Library Association: JMLA, 104, 240-243.

Breidenstine, A. S. (2004). Protective factors in the lives of children experiencing the risks of poverty and maternal depression, Doctoral Dissertation. Available from ProQuest Dissertations \& Theses database, UMI No. 3131449.

Bubonya, M., Cobb-Clark, D. A., \& Wooden, M. (2017). Job loss and the mental health of spouses and adolescent children. IZA Journal of Labor Economics, 6, 6.

Buheji, M., da Costa Cunha, K., Beka, G., Mavric, B., de Souza, Y. L., da Costa Silva, S. S., ... \& Yein, T. C. (2020). The extent of covid-19 pandemic socio-economic impact on global poverty. A global integrative multidisciplinary review. American Journal of Economics, 10(4), 213-224.

Chase-Lansdale, P. L., Moffitt, R. A., Lohman, B. J., Cherlin, A. J., Coley, R. L., Pittman, L. D., et al. (2003). Mothers' transitions from welfare to work and the well-being of preschoolers and adolescents. Science, 299, 1548-1552.

Chase-Lansdale, P. L., Cherlin, A. J., Guttmannova, K., Fomby, P., Ribar, D. C., \& Coley, R. L. (2011). Long-term implications of welfare reform for the development of adolescents and young adults. Children and Youth Services Review, 33, 678-688. 
Chatterji, P., Lahiri, K., \& Song, J. (2013). The dynamics of incomerelated health inequality among American children. Health Economics, 22, 623-629.

Chen, E., Martin, A. D., \& Matthews, K. A. (2007). Trajectories of socioeconomic status across children's lifetime predict health. Pediatrics, 120, e297-e303.

Choi, Y., Shin, J., Cho, K. H., \& Park, E. C. (2017). Change in household income and risk for attention deficit hyperactivity disorder during childhood: A nationwide population-based cohort study. Journal of Epidemiology, 27, 56-62.

Condliffe, S., \& Link, C. R. (2008). The relationship between economic status and child health: Evidence from the United States. American Economic Review, 98, 1605-1618.

Costello, E. J., Compton, S. N., Keeler, G., \& Angold, A. (2003). Relationships between poverty and psychopathology: A natural experiment. JAMA, 290, 2023-2029.

Côté-Lussier, C., Fitzpatrick, C., Séguin, L., \& Barnett, T. A. (2015). Poor, unsafe, and overweight: The role of feeling unsafe at school in mediating the association among poverty exposure, youth screen time, physical activity, and weight status. American Journal of Epidemiology, 182, 67-79.

Currie, J., \& Stabile, M. (2003). Socioeconomic status and child health: Why is the relationship stronger for older children? American Economic Review, 93, 1813-1823.

Curtis, A. C. (2015). Defining adolescence. Journal of Adolescent and Family Health, 7(2), 2.

Dearing, E., McCartney, K., \& Taylor, B. A. (2001). Change in family income-to-needs matters more for children with less. Child Development, 72, 1779-1793.

Dearing, E., McCartney, K., \& Taylor, B. A. (2006). Within-child associations between family income and externalizing and internalizing problems. Developmental Psychology, 42, 237-252.

Demment, M. M. (2013). Understanding the underlying social, maternal, and environmental risk factors for the development of overweight and obesity from birth to adolescence. Doctoral Dissertation. Available from ProQuest Dissertations \& Theses database, UMI No. 3536770.

Demment, M. M., Haas, J. D., \& Olson, C. M. (2014). Changes in family income status and the development of overweight and obesity from 2 to 15 years: A longitudinal study. BMC Public Health, $14,417$.

Eamon, M. K. (1999). A structural model of the effects of poverty on the socio-emotional development of children. Doctoral Dissertation. Available from ProQuest Dissertations \& Theses database, UMI No. 9838705.

Eamon, M. K. (2000). Structural model of the effects of poverty on externalizing and internalizing behaviors of four-to five-year-old children. Social Work Research, 24, 143-154.

Ettinger, A. K., Riley, A. W., \& Price, C. E. (2018). Increasing maternal employment influences child overweight/obesity among ethnically diverse families. Journal of Family Issues, 39, 2836-2861.

Fitzsimons, E., Goodman, A., Kelly, E., \& Smith, J. P. (2017). Poverty dynamics and parental mental health: Determinants of childhood mental health in the UK. Social Science \& Medicine, 175, 43-51.

Franco, A., Malhotra, N., \& Simonovits, G. (2014). Publication bias in the social sciences: Unlocking the file drawer. Science, 345(6203), $1502-1505$.

Fuji, M. (2012). Three essays on the determinants of children's health. Doctoral Dissertation. Available from ProQuest Dissertations \& Theses database, UMI No. 3501118.

Ginsburg, C., Griffiths, P. L., Richter, L. M., \& Norris, S. A. (2013). Residential mobility, socioeconomic context and body mass index in a cohort of urban South African adolescents. Health \& Place, 19, 99-107.

Goodman, E., Adler, N. E., Kawachi, I., Frazier, A. L., Huang, B., \& Colditz, G. A. (2001). Adolescents' perceptions of social status:
Development and evaluation of a new indicator. Pediatrics, 108(2), e31-e31.

Hackenhaar, M. L., Sichieri, R., Muraro, A. P., Gonçalves da Silva, R. M. V., \& Ferreira, M. G. (2013). Social mobility, lifestyle and body mass index in adolescents. Revista de Saúde Pública, 47, $1-9$.

Hackman, D. A., Gallop, R., Evans, G. W., \& Farah, M. J. (2015). Socioeconomic status and executive function: Developmental trajectories and mediation. Developmental Science, 18, 686-702.

Hallal, P. C., Clark, V. L., Assunção, M. C., Araújo, C. L., Gonçalves, H., Menezes, A. M., \& Barros, F. C. (2012). Socioeconomic trajectories from birth to adolescence and risk factors for noncommunicable disease: Prospective analyses. Journal of Adolescent Health, 51, S32-S37.

Holmes, J., \& Kiernan, K. (2013). Persistent poverty and children's development in the early years of childhood. Policy \& Politics, 41, 19-42.

Hope, S., Pearce, A., Whitehead, M., \& Law, C. (2014). Family employment and child socioemotional behavior: Longitudinal findings from the UK Millennium Cohort Study. Journal of Epidemiology and Community Health, 68, 950-957.

Im, Y. (2014). Causal links between maternal employment and early childhood development within low-income families. Doctoral Dissertation. Available from ProQuest Dissertations \& Theses database, UMI No. 3568549.

James-Todd, T., Tehranifar, P., Rich-Edwards, J., Titievsky, L., \& Terry, M. B. (2010). The impact of socioeconomic status across early life on age at menarche among a racially diverse population of girls. Annals of Epidemiology, 20, 836-842.

Jo, Y. (2018). Does the earned income tax credit increase children's weight? The impact of policy-driven income on childhood obesity. Health Economics, 27, 1089-1102.

Jones, A. (2018). Parental socioeconomic instability and child obesity. Biodemography and Social Biology, 64, 15-29.

Jyoti, D. F., Frongillo, E. A., \& Jones, S. J. (2005). Food insecurity affects school children's academic performance, weight gain, and social skills. The Journal of Nutrition, 135, 2831-2839.

Kagura, J., Adair, L. S., Pisa, P. T., Griffiths, P. L., Pettifor, J. M., \& Norris, S. A. (2016). Association of socioeconomic status change between infancy and adolescence, and blood pressure, in South African young adults: Birth to Twenty Cohort. British Medical Journal Open, 6, e008805.

Kakinami, L., Gauvin, L., Séguin, L., Lambert, M., Nikiema, B., \& Paradis, G. (2014a). Persistent and occasional poverty and children's food consumption: Evidence from a longitudinal Quebec birth cohort. Journal of Epidemiology and Community Health, 68, 987-992.

Kakinami, L., Séguin, L., Lambert, M., Gauvin, L., Nikiema, B., \& Paradis, G. (2014b). Poverty's latent effect on adiposity during childhood: Evidence from a Quebec birth cohort. Journal of Epidemiology and Community Health, 68, 239-245.

Kendzor, D. E., Caughy, M. O., \& Owen, M. T. (2012). Family income trajectory during childhood is associated with adiposity in adolescence: A latent class growth analysis. BMC Public Health, 12, 611.

Kiernan, K. E., \& Mensah, F. K. (2009). Poverty, maternal depression, family status and children's cognitive and behavioral development in early childhood: A longitudinal study. Journal of Social Policy, 38, 569-588.

Kozyrskyj, A. L., Kendall, G. E., Jacoby, P., Sly, P. D., \& Zubrick, S. R. (2010). Association between socioeconomic status and the development of asthma: Analyses of income trajectories. American Journal of Public Health, 100, 540-546.

Lai, E. T., Wickham, S., Law, C., Whitehead, M., Barr, B., \& Taylor-Robinson, D. (2019). Poverty dynamics and health in late 
childhood in the UK: Evidence from the Millennium Cohort Study. Archives of Disease in Childhood, 104, 1049-1055.

Lee, D. W., Shin, J., Choi, D.-W., Kim, K., \& Park, E. C. (2019). Effects of household income change on children's problem behavior: Findings from a longitudinal study. Journal of Adolescent Health, 65, 527-535.

Margerison-Zilko, C. E., \& Cubbin, C. (2013). Dynamic poverty experiences and development of overweight in a prospective cohort of US children aged 4-14 years. Obesity, 21, 1438-1445.

Martin, M. A., Lippert, A. M., Chandler, K. D., \& Lemmon, M. (2018). Does mothers' employment affect adolescents' weight and activity levels? Improving our empirical estimates. SSM-Population Health, 4, 291-300.

Mazza, J. R. S., Lambert, J., Zunzunegui, M. V., Tremblay, R. E., Boivin, M., \& Côté, S. M. (2017). Early adolescence behavior problems and timing of poverty during childhood: A comparison of lifecourse models. Social Science \& Medicine, 177, 35-42.

McGowan, J., Sampson, M., Salzwedel, D. M., Cogo, E., Foerster, V., \& Lefebvre, C. (2016). PRESS peer review of electronic search strategies: 2015 guideline statement. Journal of Clinical Epidemiology, 75, 40-46.

McKenna, C., Law, C., \& Pearce, A. (2017). Increased household financial strain, the Great Recession and child health: Findings from the UK Millennium Cohort Study. British Medical Journal Open, 7, e015559.

McLeod, J. D., \& Shanahan, M. J. (1996). Trajectories of poverty and children's mental health. Journal of Health and Social Behavior, 37, 207-220.

McMunn, A., Kelly, Y., Cable, N., \& Bartley, M. (2012). Maternal employment and child socio-emotional behavior in the UK: Longitudinal evidence from the UK Millennium Cohort Study. Journal of Epidemiology and Community Health, 66, e19-e19.

Menezes, A. M., Dumith, S. C., Perez-Padilla, R., Noal, R. B., Wehrmeister, F. C., Martínez-Mesa, J., et al. (2011). Socioeconomic trajectory from birth to adolescence and lung function: Prospective birth cohort study. BMC Public Health, 11, 596.

Miller, P., \& Votruba-Drzal, E. (2017). The role of family income dynamics in predicting trajectories of internalizing and externalizing problems. Journal of Abnormal Child Psychology, 45, $543-556$.

Min, J., Xue, H., \& Wang, Y. (2018). Association between household poverty dynamics and childhood overweight risk and health behaviors in the United States: A 8-year nationally representative longitudinal study of 16800 children. Pediatric Obesity, 13, 590-597.

Moore, K. A., Glei, D. A., Driscoll, A. K., Zaslow, M. J., \& Redd, Z. (2002). Poverty and welfare patterns: Implications for children. Journal of Social Policy, 31, 207-227.

Moustgaard, H., Avendano, M., \& Martikainen, P. (2018). Parental unemployment and offspring psychotropic medication purchases: A longitudinal fixed-effects analysis of 138,644 adolescents. American Journal of Epidemiology, 187, 1880-1888.

Muraro, A. P., Gonçalves-Silva, R. M. V., Ferreira, M. G., \& Sichieri, R. (2016). Effects of social mobility from childhood to adolescence on BMI. Public Health Nutrition, 19, 814-821.

NICHHDECCRN. (2005). Duration and developmental timing of poverty and children's cognitive and social development from birth through third grade. Child Development, 76, 795-810.

Noonan, K., Burns, R., \& Violato, M. (2018). Family income, maternal psychological distress and child socio-emotional behavior: Longitudinal findings from the UK Millennium Cohort Study. SSMPopulation Health, 4, 280-290.

Oddo, V. M., \& Jones-Smith, J. C. (2015). Gains in income during early childhood are associated with decreases in BMI z scores among children in the United States. The American Journal of Clinical Nutrition, 101, 1225-1231.
Page, A., Lewis, G., Kidger, J., Heron, J., Chittleborough, C., Evans, J., \& Gunnell, D. (2014). Parental socio-economic position during childhood as a determinant of self-harm in adolescence. Social Psychiatry and Psychiatric Epidemiology, 49, 193-203.

Peres, M. A., Peres, K. G., De Barros, A. J. D., \& Victora, C. G. (2007). The relation between family socioeconomic trajectories from childhood to adolescence and dental caries and associated oral behaviors. Journal of Epidemiology \& Community Health, 61, 141-145.

Peres, M. A., Liu, P., Demarco, F. F., Silva, A. E. R., Wehrmeister, F. C., Menezes, A. M., \& Peres, K. G. (2018). Income trajectories affect treatment of dental caries from childhood to young adulthood: A birth cohort study. Brazilian Oral Research, 32, e36.

Petterson, S. M., \& Albers, A. B. (2001). Effects of poverty and maternal depression on early child development. Child Development, 72, 1794-1813.

Poonawalla, I. B., Kendzor, D. E., Owen, M. T., \& Caughy, M. O. (2014). Family income trajectory during childhood is associated with adolescent cigarette smoking and alcohol use. Addictive Behaviors, 39, 1383-1388.

Raffington, L., Prindle, J. J., \& Shing, Y. L. (2018). Income gains predict cognitive functioning longitudinally throughout later childhood in poor children. Developmental Psychology, 54, 1232.

Rajmil, L., De Sanmamed, M. J. F., Choonara, I., Faresjö, T., Hjern, A., Kozyrskyj, A. L., ... \& Taylor-Robinson, D. (2014). Impact of the 2008 economic and financial crisis on child health: A systematic review. International Journal of Environmental Research and Public Health, 11(6), 6528-6546.

Reinhard, E., Layte, R., McCrory, C., Panico, L., \& Avendano, M. (2018). The great recession and the health of young children: A fixed-effects analysis in Ireland. American Journal of Epidemiology, 187, 1438-1448.

Ross, E.C. (2019). How parents matter: The role of mothers' education and parenting in young children's development among economically disadvantaged families. Doctoral Dissertation. Available from ProQuest Dissertations \& Theses database, UMI No. 10929847.

Russell, A. E., Ford, T., \& Russell, G. (2018). The relationship between financial difficulty and childhood symptoms of attention deficit/ hyperactivity disorder: A UK longitudinal cohort study. Social Psychiatry and Psychiatric Epidemiology, 53, 33-44.

Schoon, I., Jones, E., Cheng, H., \& Maughan, B. (2012). Family hardship, family instability, and cognitive development. Journal of Epidemiology and Community Health, 66, 716-722.

Séguin, L., Nikiéma, B., Gauvin, L., Zunzunegui, M. V., \& Xu, Q. (2007). Duration of poverty and child health in the Quebec Longitudinal Study of Child Development: Longitudinal analysis of a birth cohort. Pediatrics, 119, e1063-e1070.

Shavers, V. L. (2007). Measurement of socioeconomic status in health disparities research. Journal of the National Medical Association, 99, 1013.

Sivertsen, B., Bøe, T., Skogen, J. C., Petrie, K. J., \& Hysing, M. (2017). Moving into poverty during childhood is associated with later sleep problems. Sleep Medicine, 37, 54-59.

Skafida, V., \& Treanor, M. C. (2014). Do changes in objective and subjective family income predict change in children's diets over time? Unique insights using a longitudinal cohort study and fixed effects analysis. Journal of Epidemiology and Community Health, 68, 534-541.

Skogen, J. C., Sivertsen, B., Hysing, M., Heradstveit, O., \& Bøe, T. (2019). Economic circumstances in childhood and subsequent substance use in adolescence: A latent class analysis: The youth@ hordaland study. Frontiers in Psychology, 10, 1115.

Strohschein, L. (2005). Household income histories and child mental health trajectories. Journal of Health and Social Behavior, 46, 359-375. 
Takeuchi, D. T., Williams, D. R., \& Adair, R. K. (1991). Economic stress in the family and children's emotional and behavioral problems. Journal of Marriage and the Family, 53, 1031-1041.

Ueda, P., Kondo, N., \& Fujiwara, T. (2015). The global economic crisis, household income and pre-adolescent overweight and underweight: A nationwide birth cohort study in Japan. International Journal of Obesity, 39, 1414-1420.

Van Aert, R. C., Wicherts, J. M., \& Van Assen, M. A. (2019). Publication bias examined in meta-analyses from psychology and medicine: A meta-meta-analysis. PLoS One, 14(4), e0215052.

Wells, G. A., Shea, B., O'Connell, D., Peterson, J., Welch, V., Losos, M., \& Tugwell, P. (2014). The Newcastle-Ottawa Scale (NOS) for assessing the quality of nonrandomised studies in meta-analyses. Retrieved from http://www.ohri.ca/programs/clinical_epidemiolo gy/oxford.asp.

Wickham, S., Whitehead, M., Taylor-Robinson, D., \& Barr, B. (2017). The effect of a transition into poverty on child and maternal mental health: A longitudinal analysis of the UK Millennium Cohort Study. The Lancet Public Health, 2, e141-e148.
Wightman, P. (2010). The effect of parental job loss on children. Doctoral Dissertation. Available from ProQuest Dissertations \& Theses database, UMI No. 3369423.

Yeung, W. J., Linver, M. R., \& Brooks-Gunn, J. (2002). How money matters for young children's development: Parental investment and family processes. Child Development, 73, 1861-1879.

Yau, D. T., Wong, M. C., Lam, K. F., \& McGrath, C. (2018). Longitudinal measurement invariance and explanatory IRT models for adolescents' oral health-related quality of life. Health and Quality of Life Outcomes, 16, 60.

Zachrisson, H. D., \& Dearing, E. (2015). Family income dynamics, early childhood education and care, and early child behavior problems in Norway. Child Development, 86, 425-440.

Publisher's Note Springer Nature remains neutral with regard to jurisdictional claims in published maps and institutional affiliations. 